CrossMark \& click for updates

Cite this: Phys. Chem. Chem. Phys., 2015, 17, 28602

Received 23rd June 2015, Accepted 28th September 2015

DOI: $10.1039 / c 5 c p 03647 j$

www.rsc.org/pccp

\title{
A DFT study of adsorption of imidazole, triazole, and tetrazole on oxidized copper surfaces: $\mathrm{Cu}_{2} \mathrm{O}(111)$ and $\mathrm{Cu}_{2} \mathrm{O}(111)-w / 0-\mathrm{Cu} \mathrm{Cus}_{\dagger}$
}

\author{
Dunja Gustinčič ${ }^{a b}$ and Anton Kokalj*a
}

\begin{abstract}
Azoles and their derivatives are known for their corrosion inhibition ability for copper. For this reason the bonding of imidazole, triazole, and tetrazole-used as archetypal models of azole corrosion inhibitors-to $\mathrm{Cu}_{2} \mathrm{O}(111)$ and $\mathrm{Cu}_{2} \mathrm{O}(111)$-w/o- $\mathrm{Cu}^{\mathrm{CUS}}$ was characterized using density functional theory (DFT) calculations. The former surface contains coordinatively-saturated (CSA) and coordinatively-unsaturated (CUS) Cu sites, whereas the latter lacks the CUS sites. We find that the molecules preferentially bond with a single unsaturated $\mathrm{N}$ atom to a surface $\mathrm{Cu}$ ion and concomitantly form a hydrogen bond with the surface $\mathrm{O}$ ion. They adsorb rather strongly at CUS sites with an adsorption energy of about $-1.6 \mathrm{eV}$ (as calculated with the PBE functional), whereas the bonding at CSA sites is about three times weaker thus being similar as on metallic $\mathrm{Cu}(111)$. The impact of van der Waals dispersion interactions on molecular adsorption bonding is also addressed. Depending on specifics of the adsorption structure, they strengthen the adsorption bonding by about $0.2-0.5 \mathrm{eV}$. Due to this specific bonding enhancement, dispersion interactions alter the relative stability of adsorption modes for tetrazole. An atomistic thermodynamics approach was used to construct two-dimensional phase diagrams for all the three molecules. In the viable range of oxygen chemical potential only three phases appear in the phase-diagrams, two of which are the high coverage $(1 \times 1)$ molecular phases (one on $\mathrm{Cu}_{2} \mathrm{O}(111)$ and the other on $\mathrm{Cu}_{2} \mathrm{O}(111)-w / o-\mathrm{Cu}^{\mathrm{Cus}}$ ) and the third is clean $\mathrm{Cu}_{2} \mathrm{O}(111)-\mathrm{w} / \mathrm{O}-\mathrm{Cu}{ }^{\mathrm{CUS}}$. The current results indicate that molecular adsorption at CUS sites is strong enough to compensate the thermodynamic deficiency of stoichiometric $\mathrm{Cu}_{2} \mathrm{O}(111)$ thus making it more stable than $\mathrm{Cu}_{2} \mathrm{O}(111)-w / O-\mathrm{Cu}^{\mathrm{CUS}}$, unless the conditions are too oxygen rich and/or for azole lean. This finding may tentatively suggest that the corrosion inhibition capability of azoles stems from their ability to passivate reactive surface sites.
\end{abstract}

\section{Introduction}

Azole molecules and their derivatives are well known for their ability to slow down the corrosion of metals, ${ }^{1,2}$ i.e., many of them are efficient corrosion inhibitors. Although the atomic scale mechanism of how organic corrosion inhibitors work is usually not known, it is widely accepted that the adsorption of inhibitors onto surfaces represents an important step in achieving the inhibitory effect. ${ }^{3}$ From this point of view, it is therefore

\footnotetext{
${ }^{a}$ Department of Physical and Organic Chemistry, Jožef Stefan Institute, Jamova 39, SI-100o Ljubljana, Slovenia. E-mail: tone.kokalj@ijs.si; Web: http://wuww.ijs.si/jisw/K3-en/Kokalj; Fax: +386-1-251-93-85; Tel: +386-1-477-35-23

${ }^{b}$ Faculty of Chemistry and Chemical Technology, University of Ljubljana,

Večna pot 113, SI-1000 Ljubljana, Slovenia

$\dagger$ Electronic supplementary information (ESI) available: Calculated surface free energies (Fig. S1), charge density difference plots of hydrogen bonds (Fig. S2), and dispersion corrected adsorption phase diagrams (Fig. S3). See DOI: 10.1039/ c5cp03647j
}

important to characterize the molecule-surface bonding, although it represents only one aspect towards the atomic-scale understanding of corrosion protection mechanisms (for a more thorough approach, which involves a deconstruction of various relevant elements and their integration into a multiscale model, see the recent paper of Taylor $\left.{ }^{4}\right)$. Moreover, the interaction of organic molecules with surfaces has also been receiving considerable attention due to its importance in many other technological applications as well as for reasons of scientific curiosity.

In previous publications, the adsorption of imidazole, triazole, and tetrazole-used as archetypal models of azole inhibitors - has been characterized on $\mathrm{Cu}(111)$ by means of DFT calculations ${ }^{5,6}$ to provide an atomic-scale insight into the chemistry of azole-copper bonding. It has been shown that neutral molecules bind weakly with $\mathrm{Cu}(111)$ via unsaturated $\mathrm{N}$ heteroatoms through the $\sigma$-type bonding and the magnitude of adsorption energy decreases from imidazole to tetrazole. However, oxide-free copper surfaces are more relevant at acidic $\mathrm{pH}$, but under other conditions copper surfaces are often oxidized. ${ }^{7}$ 
In order to explain how the adsorption bonding of azole molecules depends on the oxidation state of copper, we extend the previous studies $^{5,6}$ by investigating the adsorption of these molecules on oxidized copper surfaces.

In general, the interaction of corrosion inhibitors has been explicitly modeled by DFT methods mainly on bare metallic surfaces; the reason is likely related to the fact that metallic surfaces are structurally and electronically simpler than oxidized surfaces. Computational DFT studies concerning the adsorption of azole inhibitors on oxidized copper surfaces are very scarce, i.e., Jiang $^{8}$ and Peljhan and Kokalj ${ }^{9,10}$ considered the adsorption of benzotriazole on $\mathrm{Cu}_{2} \mathrm{O}$, and Blajiev and Hubin ${ }^{11}$ considered two thiadiazole derivatives. But several other studies modeled adsorption of probe molecules on $\mathrm{Cu}_{2} \mathrm{O}$, such as $\mathrm{CO}, \mathrm{NO}, \mathrm{H}_{2} \mathrm{O}$ and $\mathrm{CO}_{2}{ }^{12-19}$ and also cylic organic molecules, such as 2-chlorophenol, ${ }^{20}$ bromobenzene, aniline ${ }^{21}$ and cyclohexanol. ${ }^{22}$ Soon $^{23}$ emphasized the importance of surface defects on copper oxide surfaces and showed that several non-stoichiometric surfaces are more stable than stoichiometric $\mathrm{Cu}_{2} \mathrm{O}(111)$. Due to this several studies of molecular adsorption were performed on non-stoichiometric surfaces. ${ }^{9,10,20,21}$

In the current paper, we investigate the bonding of imidazole, triazole, and tetrazole (their molecular structures are shown in Scheme 1) on $\mathrm{Cu}_{2} \mathrm{O}(111)$ and $\mathrm{Cu}_{2} \mathrm{O}(111)-w / o-\mathrm{Cu}^{\text {CUS }}$ surfaces; the latter surface is considered, because it is thermodynamically more stable than the former in ambient oxygen atmosphere. $^{23}$ The difference between the two surfaces is that the latter lacks the coordinatively unsaturated (CUS) Cu sites; the notation $\mathrm{Cu}_{2} \mathrm{O}(111)-w / o-\mathrm{Cu}^{\mathrm{CUS}}$ thus stands for " $\mathrm{Cu}_{2} \mathrm{O}(111)$ without the Cu CUS sites". Molecular adsorption is currently considered at a solid/vacuum interface, although in the context of corrosion inhibition it would be more appropriate to consider adsorption at a solid/water interface. This choice is due to obvious modeling reasons, and moreover because the adsorption from an aqueous phase is a rather involved phenomenon with a number of competitive effects, such as molecule-surface, molecule-water, and surface-water interactions. Hence, it is appropriate to start with a simpler system that allows a more direct chemical characterization of the

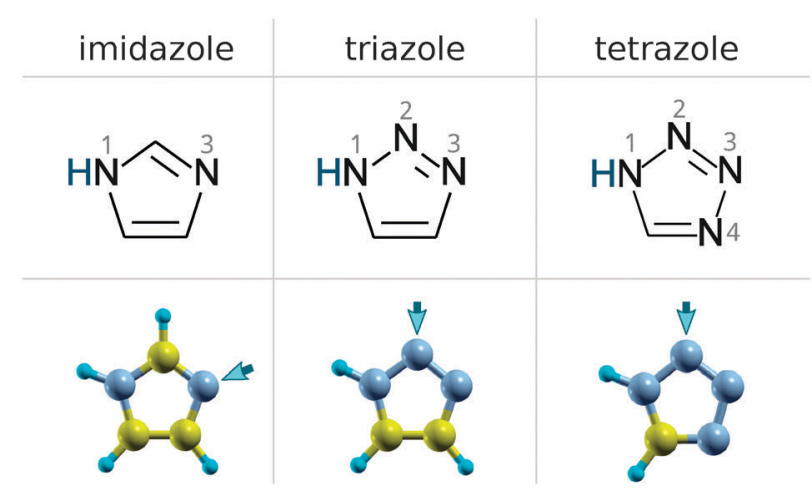

Scheme 1 Skeletal formulae of imidazole, triazole, and tetrazole with the numbering of $\mathrm{N}$ atoms (top) and ball-and-stick models of optimized molecular structures (bottom). The arrows indicate the $\mathrm{N}$ atoms that preferentially bond with the considered $\mathrm{Cu}_{2} \mathrm{O}$ surfaces (see Section 3). molecule- $\mathrm{Cu}_{2} \mathrm{O}$ bonding, which is the issue that the current paper is targeted at.

\section{Technical details}

\subsection{Computational}

The calculations were performed in the framework of DFT using the generalized gradient approximation (GGA) of Perdew-BurkeErnzerhof (PBE). ${ }^{24}$ In addition to the plain PBE functional, adsorption calculations were also performed using a PBE-D ${ }^{\prime \prime}$ functional, which includes a reparametrized empirical dispersion correction of Grimme ${ }^{25,26}$ that consists of a damped $C_{6} R^{-6}$ like energy term on top of the PBE. The double prime in the PBE- $\mathrm{D}^{\prime \prime}$ label is used to indicate the reparametrization of the original method. This reparametrization is slightly different from our previous PBE- $\mathrm{D}^{\prime}$ reparametrization of ref. $27, \neq$ which was also used in ref. 9, 10 and 31-34. By default, all the presented results refer to the PBE functional, unless explicitly stated otherwise.

A pseudopotential method with ultrasoft pseudopotentials was used. ${ }^{35,36}$ All calculations were done using the PWscf code from the Quantum ESPRESSO distribution, ${ }^{37}$ whereas visualization and molecular graphics were produced by the XCRYSDEN graphical package. ${ }^{38}$ The Kohn-Sham orbitals were expanded in a plane-wave basis set up to a kinetic energy cutoff of 30 Ry (240 Ry for the charge density cutoff). Brillouin zone (BZ) integrations were performed employing the special-point technique ${ }^{39}$ using a Marzari-Vanderbilt cold smearing ${ }^{40}$ of 0.01 Ry.

\subsection{Model of oxidized copper surfaces}

Oxidized copper surfaces were modeled by $\mathrm{Cu}_{2} \mathrm{O}$ slabs without a metal support underneath. This model is appropriate for cases where the oxide layer on top of metal is not ultrathin, because the reactivity of few $\AA$ thick oxide films supported on metals can be very different from the reactivity of surfaces of bulk oxides. ${ }^{41}$ In a recent study, ${ }^{42}$ the average thicknesses of $\mathrm{Cu}_{2} \mathrm{O}$ oxide layers formed on $\mathrm{Cu}$ immersed in $3 \mathrm{wt} \% \mathrm{NaCl}$ solution were estimated to be about $2.2 \pm 0.3 \mathrm{~nm}$ for the noninhibited sample and $1.3 \pm 0.2 \mathrm{~nm}$ for the sample inhibited by benzotriazole. These thicknesses seem therefore sufficient to make the current model adequate.

$\ddagger$ The reason for the reparametrization is that the original PBE-D overestimates a molecular bonding to copper surfaces, ${ }^{27-30}$ which can be attributed to a too large $C_{6}$ value of a $\mathrm{Cu}$ atom. ${ }^{29}$ Both the PBE-D ${ }^{\prime}$ and the current PBE-D" are re-parametrized so as to match the experimental adsorption energy of a flat lying benzene on $\mathrm{Cu}(111)$. For PBE-D' ${ }^{\prime}$ this was achieved in a dirty way by adjusting the $s_{6}$ scaling parameter to the value of 0.47 (the original value is 0.75 ), because the Quantum ESPRESSO code did not allow to set the $C_{6}$ values in the input. Consequently, PBE-D' cannot handle well the lateral molecule-molecule dispersion interactions and is therefore mainly applicable for the molecule copper bonding at low coverage. In contrast, for PBE- ${ }^{\prime \prime}$ the Quantum ESPRESSO code was modified to allow the specification of $C_{6}$ parameters in the input and the $C_{6}$ parameter of $\mathrm{Cu}$ was set to the value of $140 \mathrm{Ry} \mathrm{Bohr}^{-6}$ (the original value is $375 \mathrm{Ry}$ $\mathrm{Bohr}^{-6}$ ), while the $s_{6}$ was kept at its original value of 0.75 . 

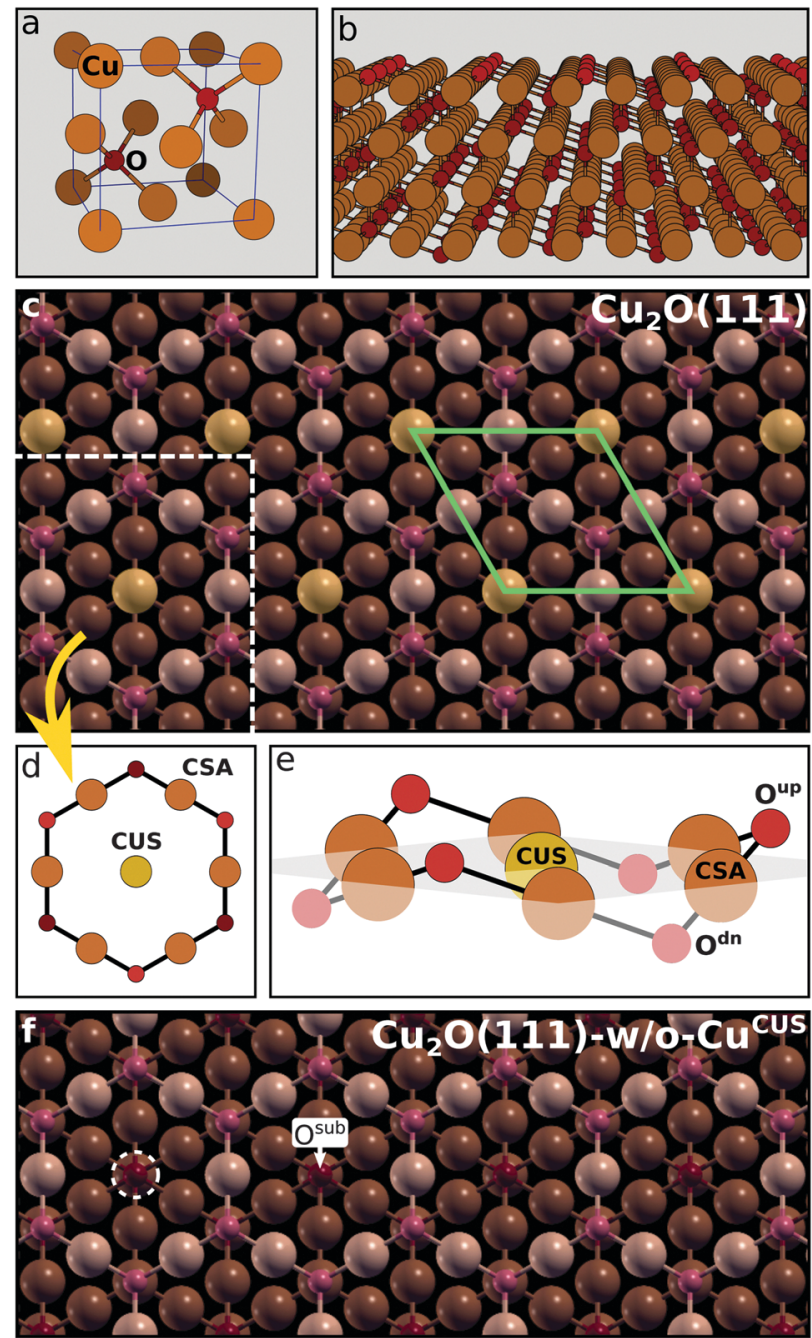

Scheme 2 (a) Unit cell of $\mathrm{Cu}_{2} \mathrm{O}$ bulk, chosen such that $\mathrm{Cu}$ is at the origin Smaller red and bigger brown balls represent $\mathrm{O}$ and $\mathrm{Cu}$ ions, respectively. (b) The side view of a four O-Cu-O trilayer thick $\mathrm{Cu}_{2} \mathrm{O}$ (111) slab. (c) The top view of $\mathrm{Cu}_{2} \mathrm{O}$ (111) with the surface $\mathrm{Cu}$ ions colored brighter; it can be seen that the surface trilayer is constructed of centered hexagons. The $(1 \times 1)$ surface cell is indicated by a greenish parallelogram. (d) Top and (e) side views of a single centered hexagon with the designation of pertinent $\mathrm{Cu}$ and $\mathrm{O}$ ions (for brevity reasons copper sites are labeled as CUS and CSA with the Cu being omitted). In (c)-(e), the CUS ions are colored a bit more yellowish than the CSA ions. (f) The top view of $\mathrm{Cu}_{2} \mathrm{O}(111)-\mathrm{w} / \mathrm{O}-\mathrm{Cu}{ }^{\mathrm{CUS}}$, which lacks the CUS sites. One CUS vacancy at the left is indicated by a white dashed circle and towards the right an $\mathrm{O}^{\text {sub }}$ ion is explicitly marked.

2.2.1 Bulk $\mathrm{Cu}_{2} \mathrm{O}$. The cuprite structure of $\mathrm{Cu}_{2} \mathrm{O}$ bulk can be seen as composed of interlaced $\mathrm{Cu}$ fcc and $\mathrm{O}$ bcc lattices, displaced by $\left(\frac{1}{4}, \frac{1}{4}, \frac{1}{4}\right)$ with respect to one another; a unit cell of $\mathrm{Cu}_{2} \mathrm{O}$ bulk is shown in Scheme $2 \mathrm{a}$ with $\mathrm{Cu}$ positioned at the origin. Each $\mathrm{O}$ ion is tetrahedrally coordinated to four $\mathrm{Cu}$ ions and each $\mathrm{Cu}$ ion is linearly coordinated with two $\mathrm{O}$ ions. The experimental lattice parameter of $\mathrm{Cu}_{2} \mathrm{O}$ is $4.27 \AA{ }^{43}$ whereas we used the calculated value of $4.35 \AA{ }^{9}$ $\mathrm{PBE}^{\prime \prime} \mathrm{D}^{\prime \prime}$ gives a lattice parameter virtually identical to that of the PBE.
2.2.2 $\mathrm{Cu}_{2} \mathrm{O}(111)$ and $\mathrm{Cu}_{2} \mathrm{O}(111)-w / o-\mathrm{Cu}^{\mathrm{CUS}}$. The structure of the $\mathrm{Cu}_{2} \mathrm{O}(111)$ surface is shown in Scheme $2 \mathrm{~b}-\mathrm{e}$. From the perspective side view (Scheme $2 b$ ) it can be seen that a $\mathrm{Cu}_{2} \mathrm{O}(111)$ slab consists of $\mathrm{O}-\mathrm{Cu}-\mathrm{O}$ trilayers, whereas the top view (Scheme 2c) reveals that the $\mathrm{Cu}_{2} \mathrm{O}(111)$ surface is tiled with centered hexagons; Scheme $2 \mathrm{~d}$ and e show top and perspective views of a single centered hexagon with the designation of respective sites. The $\mathrm{Cu}_{2} \mathrm{O}(111)$ surface contains two chemically distinct $\mathrm{Cu}$ ions, a coordinatively saturated (CSA) and coordinatively unsaturated (CUS); the Cu CUS ions are colored a bit more yellowish in Scheme 2c-e than the $\mathrm{Cu}$ CSA ions, which are colored brown. Each CUS is bonded with an O ion directly beneath it, but this $\mathrm{O}$ ion is not shown in Scheme 2e. Each CSA is bonded with one $\mathrm{O}^{\text {up }}$ and one $\mathrm{O}^{\mathrm{dn}}$ ion; the former is located above and the latter below the plane of surface $\mathrm{Cu}$ ions.

The structure of $\mathrm{Cu}_{2} \mathrm{O}(111)-\mathrm{w} / \mathrm{o}-\mathrm{Cu}$ CUS , which lacks the CUS sites, is shown in Scheme 2f. The $\mathrm{O}$ ions below the CUS vacancies are labeled as $\mathrm{O}^{\text {sub }}$ ("sub" stands for subsurface; both the CUS vacancies and $\mathrm{O}^{\text {sub }}$ are indicated in Scheme $2 \mathrm{f}$ ). Although $\mathrm{Cu}_{2} \mathrm{O}(111)-\mathrm{w} / \mathrm{o}-\mathrm{Cu}^{\mathrm{CUS}}$ displays a sizable magnetic moment (e.g., about $1 \mu_{\mathrm{B}}$ per CUS vacancy ${ }^{44}$ ), several test calculations revealed that the effect of magnetism on the total energy is marginal, ${ }^{9}$ hence all the presented results refer to spin unpolarized slab calculations.

\subsection{Surface free energy calculations}

Surface free energies were calculated using symmetric $(1 \times 1)$ slabs in which both surfaces are equivalent. The slabs consisting of 6,7 , and $9 \mathrm{O}-\mathrm{Cu}-\mathrm{O}$ trilayers were used. The in-plane lattice spacing was fixed to the calculated equilibrium bulk lattice parameter, while other degrees of freedom were relaxed. The BZ integrations were performed using a $3 \times 3 \times 1$ uniformly shifted $k$-mesh.

It has been shown that to a first approximation total energies can be used to represent Gibbs free energies of solids, ${ }^{23,45}$ hence the surface free energies $\left(\gamma_{\text {surf }}\right)$ were calculated by fitting the equation: ${ }^{9}$

$$
E_{\text {slab }}\left(N_{\text {tl }}\right)=2 A \gamma_{\text {surf }}+N_{\text {tl }} E_{\text {tl }}+\Delta N_{\mathrm{O}}^{\text {stoich }} \mu_{\mathrm{O}},
$$

for several values of $N_{\mathrm{tl}}$, where $N_{\mathrm{tl}}$ is the number of $\mathrm{O}-\mathrm{Cu}-\mathrm{O}$ trilayers in a (111) slab, $E_{\text {slab }}$ is the total energy of the slab, $A$ is the area spanned by a supercell (factor 2 comes from the fact that a slab has two equivalent surfaces), $E_{\mathrm{tl}}$ is the total energy of a single trilayer in the bulk, $\mu_{\mathrm{O}}$ is the chemical potential of oxygen, and $\Delta N_{\mathrm{O}}^{\text {stoich }}$ is the number of excess $\mathrm{O}$ atoms, i.e.,

$$
\Delta N_{\mathrm{O}}^{\text {stoich }}=N_{\mathrm{O}}-\frac{N_{\mathrm{Cu}}}{2}
$$

where $N_{\mathrm{O}}$ and $N_{\mathrm{Cu}}$ are the number of $\mathrm{O}$ and $\mathrm{Cu}$ ions in the slab, respectively. $\Delta N_{\mathrm{O}}^{\text {stoich }}$ accounts for the non-stoichiometry of the slab. Note that $\gamma_{\text {surf }}$ depends on the $\mu_{\mathrm{O}}$ only for non-stoichiometric slabs (i.e., $\mathrm{Cu}_{2} \mathrm{O}(111)-\mathrm{w} / \mathrm{o}-\mathrm{Cu}{ }^{\mathrm{CUS}}$ ) for which $\Delta N_{\mathrm{O}}^{\text {stoich }} \neq 0$.

While plotting the $\gamma_{\text {surf }}$ as a function of $\mu_{\mathrm{O}}$, a viable range of $\mu_{\mathrm{O}}$ should be considered. The oxygen poor $\left(\mathrm{O}_{\text {lean }}\right)$ and rich 
$\left(\mathrm{O}_{\text {rich }}\right)$ limits§ are chosen according to eqn (3a) and (3b), respectively: ${ }^{23,45}$

$$
\begin{gathered}
\mu_{\mathrm{O}}^{\min }=E_{\mathrm{Cu}_{2} \mathrm{O}}^{\text {bulk }}-2 E_{\mathrm{Cu}}^{\mathrm{bulk}} \text { and } \mu_{\mathrm{Cu}}^{\max }=E_{\mathrm{Cu}}^{\text {bulk }}, \\
\mu_{\mathrm{O}}^{\max }=\frac{1}{2} E_{\mathrm{O}_{2}} \quad \text { and } \quad \mu_{\mathrm{Cu}}^{\min }=\frac{1}{2}\left[E_{\mathrm{Cu}_{2} \mathrm{O}}^{\mathrm{bulk}}-\frac{1}{2} E_{\mathrm{O}_{2}}\right],
\end{gathered}
$$

where $E_{\mathrm{Cu}}^{\text {bulk }}$ and $E_{\mathrm{O}_{2}}$ are the total energies of $\mathrm{Cu}$ atoms in the $\mathrm{Cu}$-bulk and isolated $\mathrm{O}_{2}$ molecule, respectively. Half of the total energy of the $\mathrm{O}_{2}$ molecule is chosen as zero reference for $\mu_{\mathrm{O}}$, i.e., $\Delta \mu_{\mathrm{O}}=\mu_{\mathrm{O}}-\frac{1}{2} E_{\mathrm{O}_{2}}$. Hence at the $\mathrm{O}_{\text {lean }}$ limit $\Delta \mu_{\mathrm{O}}=-1.27 \mathrm{eV}$ and at the $\mathrm{O}_{\text {rich }}$ limit $\Delta \mu_{\mathrm{O}}=0 \mathrm{eV}$. If the surface is in ambient gas phase, the $\mu_{\mathrm{O}}$ depends on the temperature, $T$, and oxygen partial pressure, $p$, which within the ideal-gas approximation can be written as $\mu_{\mathrm{O}}(T, p)=\mu\left(T, p^{0}\right)+\frac{1}{2} k T \ln \left(p / p^{0}\right)$, where $p^{0}$ stands for a standard pressure and $k$ is the Boltzmann constant. This implies that low values of $\mu_{\mathrm{O}}$ correspond to high $T$ and low $p$ (vice versa for the high values of $\mu_{\mathrm{O}}$ ).

\subsection{Adsorption calculations}

The adsorption calculations were performed using slabs consisting of four $\mathrm{O}-\mathrm{Cu}-\mathrm{O}$ trilayers. The molecules were adsorbed on the top side of the slab and a dipole correction of Bengtsson ${ }^{46}$ was applied to cancel an artificial electric field that develops along the direction normal to the slab due to periodic boundary conditions imposed on the electrostatic potential. The thickness of the vacuum region-the distance between the top of ad-molecules and the adjacent slab-was set to about $20 \AA$. Adsorption properties were calculated with $(1 \times 1),(2 \times 2)$, and $(3 \times 3)$ supercells, using the $3 \times 3 \times 1,2 \times 2 \times 1$, and $1 \times$ $1 \times 1$ uniformly shifted $k$-meshes for the BZ integrations, respectively.

The adsorption energy was calculated as:

$$
E_{\mathrm{ads}}=E_{\mathrm{mol} / \mathrm{slab}}-\left(E_{\mathrm{slab}}+E_{\mathrm{mol}}\right)
$$

where $E_{\mathrm{mol}}, E_{\mathrm{slab}}$, and $E_{\mathrm{mol} / \mathrm{slab}}$ are the total energies of the isolated molecule, slab, and molecule/slab systems, respectively; "mol" will be used as a generic label to indicate a molecule.

Thermodynamic stability of adsorption structures that differ in surface coverage is evaluated by means of the adsorption surface free energy, $\gamma_{\text {ads }}$, as a function of the molecular chemical potential, $\mu_{\mathrm{mol}}$. To a first approximation $\gamma_{\text {ads }}$ can be related to adsorption energy and $\mu_{\mathrm{mol}}$ via the relation:

$$
\gamma_{\mathrm{ads}}\left(\mu_{\mathrm{mol}}\right) \approx \frac{n}{A}\left(E_{\mathrm{ads}}-\Delta \mu_{\mathrm{mol}}\right)
$$

where $n$ is the number of adsorbed molecules per supercell and $\Delta \mu_{\mathrm{mol}}=\mu_{\mathrm{mol}}-E_{\mathrm{mol}}$. The important point of eqn (5) is that $\gamma_{\mathrm{ads}}$ is a linear function of $\mu_{\mathrm{mol}}$ with the slope being proportional to

$\S$ The oxygen poor limit can be defined as a point where the bulk $\mathrm{Cu}_{2} \mathrm{O}$ decomposes into bulk $\mathrm{Cu}$ and $\mathrm{O}_{2}$ gas, whereas at the oxygen rich limit oxygen gas condenses on the surface. the negative of the (absolute) surface coverage, $-n / A$. This implies that the larger the coverage the steeper is the slope of the corresponding $\gamma_{\text {ads }}$ line. Thermodynamically the most stable structure at a given $\mu_{\mathrm{mol}}$ is the one that displays the lowest adsorption surface free energy.

The stabilization of surface free energy due to a molecular adsorption can be estimated as:

$$
\tilde{\gamma}_{\text {surf }}\left(\mu_{\mathrm{O}}\right) \approx \gamma_{\text {surf }}\left(\mu_{\mathrm{O}}\right)+\varepsilon_{\mathrm{ads}},
$$

where $\varepsilon_{\text {ads }}$ is the molecular adsorption energy per unit area:

$$
\varepsilon_{\mathrm{ads}}=\frac{n E_{\mathrm{ads}}}{A} .
$$

Hence the more exothermic the $\varepsilon_{\text {ads }}$, the more the surface stabilized.

The one-dimensional treatment of eqn (5) can be extended by treating the adsorption surface free energy as a twodimensional function of $\mu_{\mathrm{mol}}$ and $\mu_{\mathrm{O}}$. We utilize the following approximate relation:

$$
\tilde{\gamma}_{\mathrm{ads}}\left(\mu_{\mathrm{mol}}, \mu_{\mathrm{O}}\right) \approx \sigma_{0}+\varepsilon_{\mathrm{ads}}-\frac{1}{A}\left[\Delta n_{\mathrm{O}}^{\text {stoich }} \Delta \mu_{\mathrm{O}}+n \Delta \mu_{\mathrm{mol}}\right],
$$

where $\Delta n_{\mathrm{O}}^{\text {stoich }}=\frac{1}{2} \Delta N_{\mathrm{O}}^{\text {stoich }}$ and $\sigma_{0}$ is the surface energy at the oxygen rich limit $\left(\Delta \mu_{\mathrm{O}}=0\right)$, i.e.,

$$
\sigma_{0} \approx \frac{1}{2 A}\left[E_{\text {slab }}-N_{\mathrm{tl}} E_{\mathrm{tl}}-\Delta N_{\mathrm{O}}^{\text {stoich }} E_{\mathrm{O}_{2}}\right]
$$

2.4.1 Other definitions. Electron charge density difference was calculated as:

$$
\Delta \rho(\mathbf{r})=\rho_{\text {mol } / \text { slab }}(\mathbf{r})-\rho_{\text {slab }}(\mathbf{r})-\rho_{\text {mol }}(\mathbf{r}),
$$

where the subscripts have the same meaning as in eqn (4). The geometries of the standalone "mol" and "slab" structures were kept the same as in the "mol/slab" system.

The local geometry of adsorption structures are specified as $N_{\text {list }}+H_{\text {bond }}$, where $N_{\text {list }}$ specifies with which $\mathrm{N}$ atoms a molecule bonds to the surface. If the adsorbed molecule also forms a hydrogen bond with the surface then the $H_{\text {bond }}$ specifier characterizes it. Here are two examples: (1) the label $\mathrm{N} 2+\mathrm{N} 1 \mathrm{H} \cdots \mathrm{O}^{\text {up }}$ indicates that a molecule bonds with its $\mathrm{N} 2$ atom to the surface and also forms the $\mathrm{N} 1-\mathrm{H} \cdots \mathrm{O}^{\text {up }}$ hydrogen bond; (2) the label N2 + N3 indicates that a molecule bonds to the surface via its $\mathrm{N} 2$ and $\mathrm{N} 3$ atoms without any hydrogen bond.

The global geometry of adsorption phases are designated either as " $(N \times N)$-mol@site" or as " $(N \times N)$-mol@surface", where $(N \times N)$ represents a periodic pattern that molecules form with respect to the surface unit-cell, site designates a specific site the molecules bond to (CSA or CUS), and surface specifies the surface $\left(\mathrm{Cu}_{2} \mathrm{O}(111)-\mathrm{w} / \mathrm{o}-\mathrm{Cu}^{\mathrm{CUS}}\right.$ or $\left.\mathrm{Cu}_{2} \mathrm{O}(111)\right)$. For example, $(3 \times 3)-\mathrm{mol} @ \mathrm{Cu}_{2} \mathrm{O}(111)-\mathrm{w} / \mathrm{o}-\mathrm{Cu}^{\mathrm{CUS}}$ stands for one molecule adsorbed per $(3 \times 3)$ supercell on $\mathrm{Cu}_{2} \mathrm{O}(111)-\mathrm{w} / \mathrm{o}-\mathrm{Cu}^{\text {CUS }}$.

Near an adsorbed molecule at the CSA site not all $\mathrm{O}^{\text {up }}$ ions are equivalent, hence a more precise naming convention of $\mathrm{O}$ ions is utilized for unambiguous specification of adsorption 


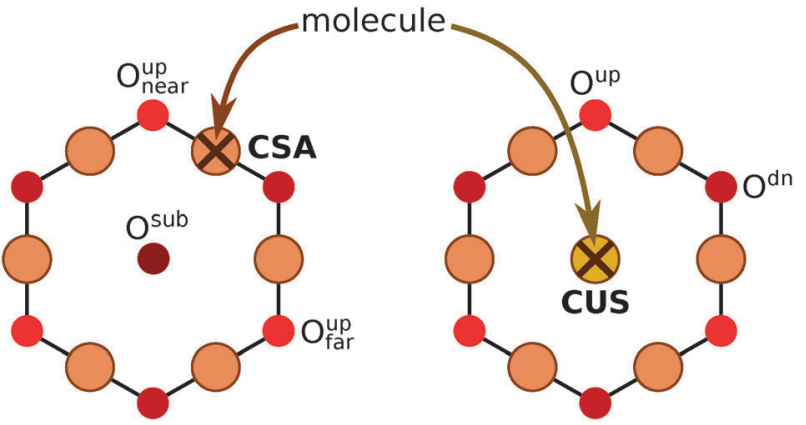

Scheme 3 Definition of various $O$ sites near an adsorbed molecule at the CSA site on $\mathrm{Cu}_{2} \mathrm{O}(111)$-w/o- $\mathrm{Cu}^{\mathrm{CUS}}$ (left) and CUS site (right). The molecule adsorbed at the CSA site can form a hydrogen bond with either $\mathrm{O}_{\text {near, }}^{\text {up }} \mathrm{O}_{\text {far, }}^{\text {up }}$ or $\mathrm{O}^{\text {sub }}$. In contrast, the molecule adsorbed at the CUS site can only form a hydrogen bond with one among the three equivalent nearby $\mathrm{O}^{\text {up }}$ ions.

structures (see Scheme 3). The molecule adsorbed at the CSA site can form a hydrogen bond with either the first or the second nearest neighbor $\mathrm{O}^{\text {up }}$ ions, which are named as $\mathrm{O}_{\text {near }}^{\text {up }}$ and $\mathrm{O}_{\mathrm{far}}^{\mathrm{up}}$, respectively. For brevity reasons, $\mathrm{O}_{\text {near }}^{\text {up }}$ will be occasionally referred implicitly as $\mathrm{O}^{\text {up }}$ (but $\mathrm{O}_{\text {far }}^{\text {up }}$ will be always referred explicitly). In contrast, for a molecule adsorbed at the CUS site there are three equivalent nearby $\mathrm{O}^{\text {up }}$ ions.

\section{Results and discussion}

The calculated surface free energies of $\mathrm{Cu}_{2} \mathrm{O}(111)$ and $\mathrm{Cu}_{2} \mathrm{O}(111)$ $\mathrm{w} / \mathrm{o}-\mathrm{Cu}^{\mathrm{CUS}}$ as a function of the oxygen chemical potential are shown in Fig. S1 in the ESI; $†$ they are in good agreement with those reported previously by Soon. ${ }^{23}$ Given that $\mathrm{Cu}_{2} \mathrm{O}(111)$ $\mathrm{w} / \mathrm{o}-\mathrm{Cu}^{\mathrm{CUS}}$ is considerably more stable than stoichiometric $\mathrm{Cu}_{2} \mathrm{O}(111)$, it is taken as a reference and a starting point for the current investigation of the adsorption of azoles on oxidized copper surfaces. This model is used to ascertain the molecular bonding at CSA sites. In addition, the adsorption is also modeled at individual CUS sites, which can be regarded as extraneous or defect sites on $\mathrm{Cu}_{2} \mathrm{O}(111)-\mathrm{w} / \mathrm{o}-\mathrm{Cu}^{\mathrm{CUs}}$; the corresponding model therefore contains only as many CUS ions as adsorbed molecules. This model is used to ascertain the molecular bonding at CUS sites.
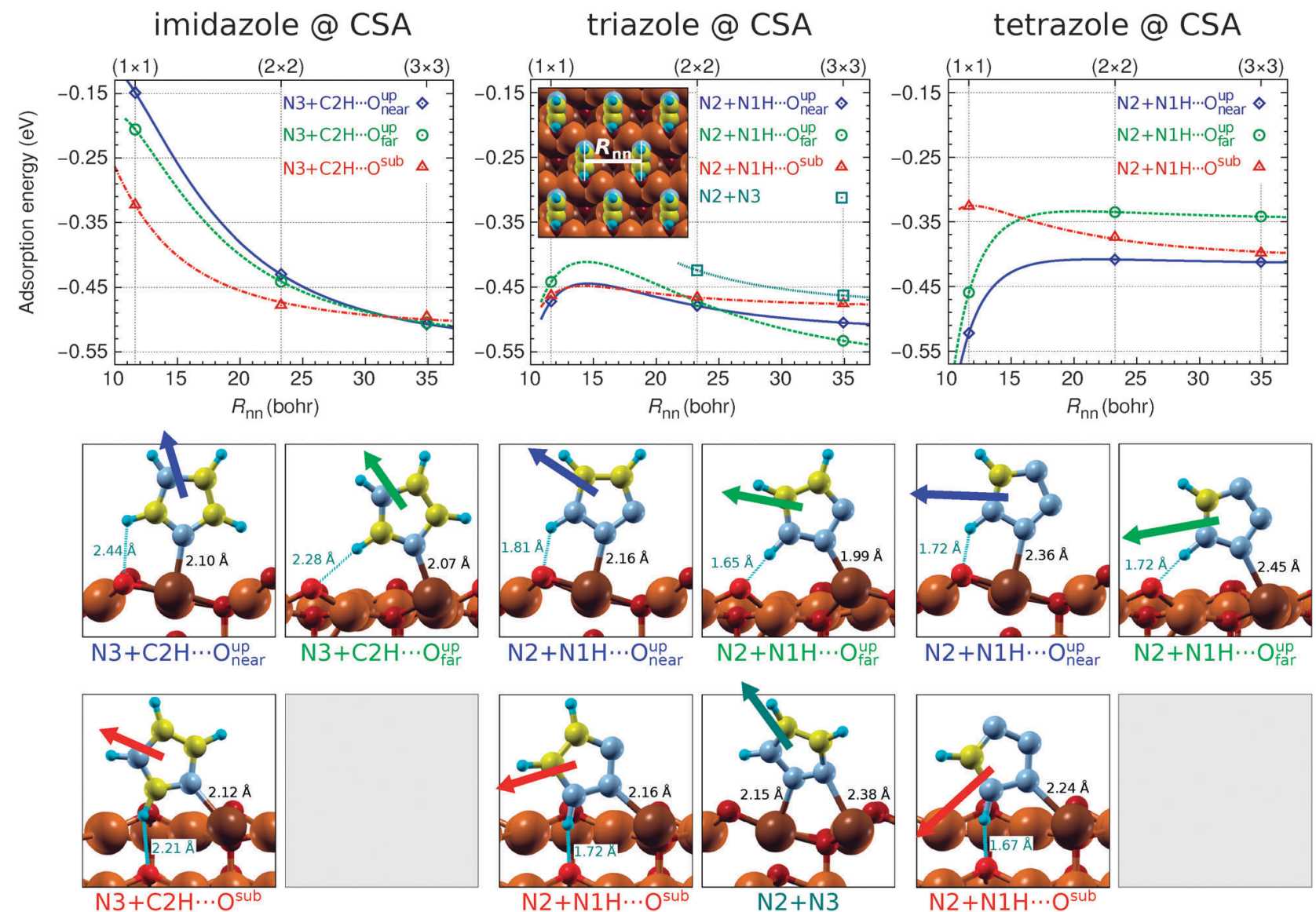

Fig. 1 Top: Adsorption energy as a function of the nearest-neighbor intermolecular distance $\left(R_{\mathrm{nn}}\right.$, defined graphically in the inset at the center) for imidazole, triazole, and tetrazole bonded at a CSA site of $\mathrm{Cu}_{2} \mathrm{O}(111)-w / 0-\mathrm{Cu}^{\mathrm{CUS}}$. Curves are mainly drawn to guide the eye to make the plots more readable; they were calculated using the polarizable point-dipole model of ref. 47 . The calculations were performed using the $(1 \times 1)$, $(2 \times 2)$, and $(3 \times 3)$ supercells. Bottom: Snapshots of pertinent adsorption modes, as obtained using the $(3 \times 3)$ supercell, superimposed with dipole vectors of isolated molecules. The corresponding $\mathrm{N}-\mathrm{Cu}$ bond lengths and $\mathrm{H} \ldots \mathrm{O}$ distances are also stated. 

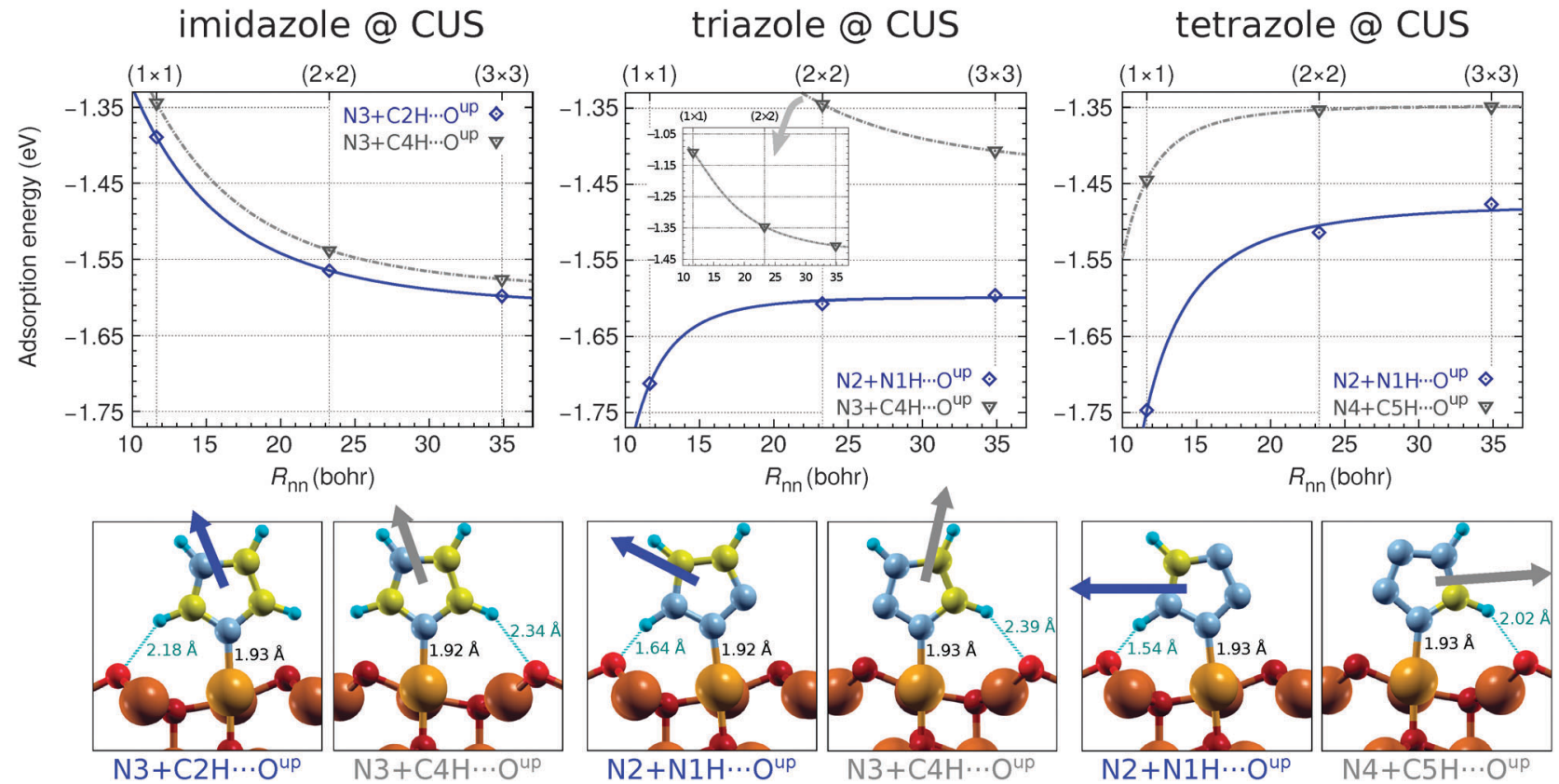

Fig. 2 As in Fig. 1 but for the molecular bonding at a CUS site. Adsorption energies are calculated with respect to the high-symmetry position of CuCUs ions in the bare substrate to better represent the molecule-surface bond strengths. Note that the $\mathrm{Cu}^{\text {cus }}$ ions of the bare substrate relax laterally to a more stable asymmetric position if the symmetry is broken (see Fig. 1 in ref. 9) with an energy stabilization of $0.13 \mathrm{eV}$ at full $(\Theta=1)$ and $0.04 \mathrm{eV}$ at lower surface concentration $(\Theta \leq 1 / 4)$ of extraneous $\mathrm{Cu}^{\text {CUS }}$ ions at $\mathrm{Cu}_{2} \mathrm{O}(111)$-w/o- $\mathrm{Cu}$ CUS .

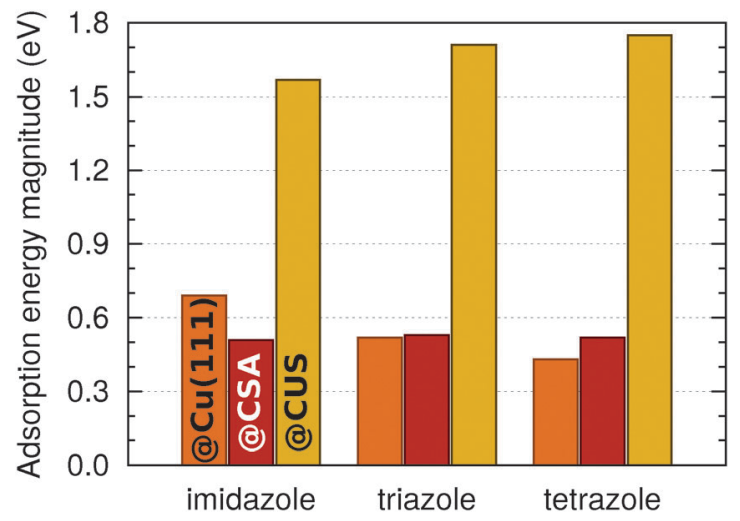

Fig. 3 Magnitudes of adsorption energies of imidazole, triazole, and tetrazole on $\mathrm{Cu}(111)$ and at the CSA and $\mathrm{CUS}$ sites of $\mathrm{Cu}_{2} \mathrm{O}$. The values for $\mathrm{Cu}(111)$ are taken from ref. 6 . Only the largest magnitudes, irrespective of the coverage, are considered for a given molecule on a given site (or surface).

\subsection{Adsorption structures and energies}

Several adsorption geometries were investigated for each molecule adsorbed at CSA and CUS sites and the corresponding results are presented in Fig. 1 and 2, respectively. These figures plot the dependence of adsorption energies on the nearest neighbor intermolecular distance, $R_{\mathrm{nn}} \cdot \uparrow$ Beneath these plots the structures of pertinent adsorption modes-optimized at the lowest considered

T The issue of dependence of $E_{\text {ads }}$ on the coverage is relevant, because azole molecules have large permanent dipole moments that can result in long-range lateral dipole-dipole interactions between adsorbed molecules. ${ }^{5,32,47}$ coverage using the $(3 \times 3)$ supercell-are shown; dipole-moment vectors of isolated molecules, oriented as in the respective adsorption state, are drawn superimposed with the adsorbed molecules and the $\mathrm{N}-\mathrm{Cu}$ and $\mathrm{H} \cdots \mathrm{O}$ bond distances are also stated. It is worth noting that currently only the adsorption of intact molecules is considered, because the dissociation of the molecular N1- $\mathrm{H}$ bond, to form $\mathrm{OH}$ with the nearby surface $\mathrm{O}$ ion (note that on the $\mathrm{Cu}_{2} \mathrm{O}$ surface an $\mathrm{H}$ binds more strongly to an $\mathrm{O}$ than a $\mathrm{Cu}$ ion), was found to be endothermic by more than $1 \mathrm{eV}$ for imidazole and over $0.1 \mathrm{eV}$ for triazole and tetrazole; this issue will be considered in more detail in the forthcoming publication.

Imidazole binds with the N3 atom to the CSA and CUS sites and forms a weak $\mathrm{C}-\mathrm{H} \cdots \mathrm{O}$ hydrogen bond with either $\mathrm{O}_{\text {near }}^{\text {up }}$, $\mathrm{O}_{\mathrm{far}}^{\mathrm{up}}$, or $\mathrm{O}^{\text {sub }}$ ion when bonded at the CSA sites (Fig. 1, left) and with the $\mathrm{O}^{\text {up }}$ ion when adsorbed at the CUS sites (Fig. 2, left). Triazole and tetrazole bind preferably with the N2 atom to the CSA and CUS sites and form a N-H $\cdots$ O hydrogen bond (Fig. 1 and 2, middle and right) which is shorter and stronger than the $\mathrm{C}-\mathrm{H} \cdots \mathrm{O}$ bond of imidazole (for the strength of these hydrogen bonds see Fig. S2 in the ESI $\dagger$ ). That the $\mathrm{N}-\mathrm{H} \cdots$ O hydrogen bond is stronger than the $\mathrm{C}-\mathrm{H} \cdots \mathrm{O}$ bond can be also inferred by comparing the adsorption energies of triazole $\mathrm{N} 2+\mathrm{N} 1 \mathrm{H} \cdots \mathrm{O}^{\text {up }}$ vs. $\mathrm{N} 3+\mathrm{C} 4 \mathrm{H} \cdots \mathrm{O}^{\text {up }}$ as well as tetrazole $\mathrm{N} 2+\mathrm{N} 1 \mathrm{H} \cdots \mathrm{O}^{\text {up }} v s . \mathrm{N} 4+$ $\mathrm{C} 5 \mathrm{H} \cdots \mathrm{O}^{\text {up }}$ structures at the CUS sites (Fig. 2, middle and right). Triazole can also bind with the $\mathrm{N} 2$ and $\mathrm{N} 3$ atoms to two neighboring CSA sites (N2 + N3 adsorption mode), but this mode is stable only at low coverage $\|$ and even then it is inferior

\|In contrast with the CSA site, at the CUS site the N2 + N3 adsorption mode is not stable, i.e., it transforms to $\mathrm{N} 2$ bonding during the geometry optimization. 
(1×1)-mol @ CUS

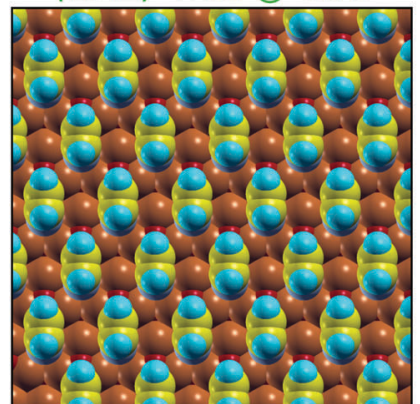

(2×2)-mol @ CUS

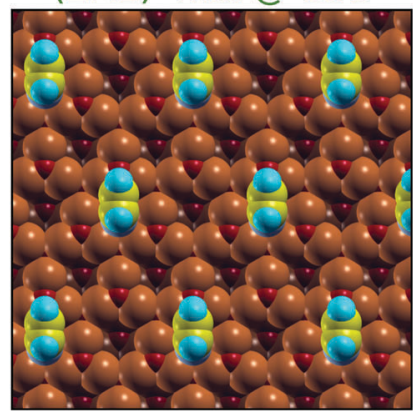

(3×3)-mol @ CUS

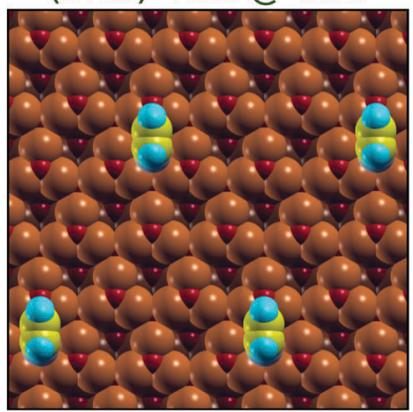

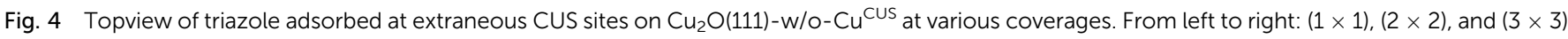

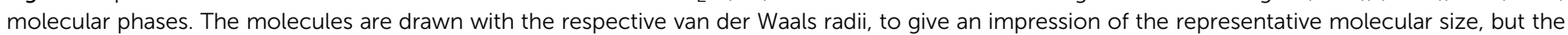

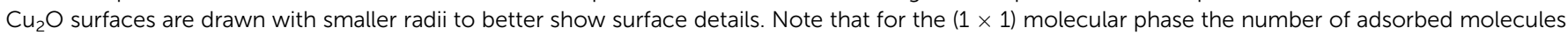

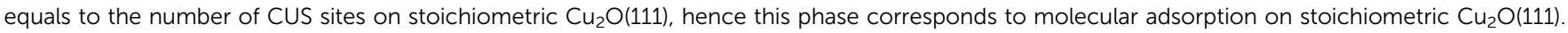

to the $\mathrm{N} 2$ bonding modes, presumably due to the lack of $\mathrm{N}-\mathrm{H} \cdots \mathrm{O}$ bonding.

While on plain metallic $\mathrm{Cu}$ surfaces the dependence of adsorption energy on the $R_{\mathrm{nn}}$ or on the coverage $(\Theta$, note that $\Theta \propto R_{\mathrm{nn}}^{-2}$ ) can be straightforwardly understood in terms of the orientation of molecular dipoles-i.e., dipoles oriented normally (parallelly) to the surface result in lateral repulsive (attractive) interactions ${ }^{5,32,47}$ - the situation is bit more complicated on the $\mathrm{Cu}_{2} \mathrm{O}(111)-w / 0-\mathrm{Cu}^{\text {CUS }}$ surface, because each $\mathrm{Cu}^{\text {CUS }}$ vacancy displays an inward pointing dipole of about $0.5 \mathrm{D}$ and it is the cumulative (molecule + vacancies) dipole that matters. Nevertheless, the orientation of molecular dipoles seems still useful to roughly understand the lateral dependence. For example, imidazole displays the most repulsive and tetrazole the most attractive lateral interactions and, indeed, the dipoles of the former point largely upright and that of the latter almost parallel to the surface, e.g., see the left and right panels of Fig. 2 and also the dipole orientation of imidazole $\mathrm{N} 3+\mathrm{C} 2 \mathrm{H} \cdots \mathrm{O}_{\text {near }}^{\text {up }}$ and tetrazole $\mathrm{N} 2+\mathrm{N} 1 \mathrm{H} \cdots \mathrm{O}_{\text {near }}^{\text {up }}$ adsorption modes in Fig. 1.

The current results reveal that molecular bonding to the CSA sites is considerably weaker than that to the CUS sites. The strongest adsorption energy for the three molecules at the CSA sites is about $-0.5 \mathrm{eV}$ (Fig. 1), whereas at the CUS sites it is more than three times stronger, being about $-1.6 \mathrm{eV}$ for imidazole, $-1.7 \mathrm{eV}$ for triazole, and $-1.75 \mathrm{eV}$ for tetrazole (Fig. 2). This stronger bonding at CUS sites is also reflected in the $\mathrm{N}-\mathrm{Cu}$ bond distances, which are about $1.9 \AA$ at the CUS site and in the range between about 2.0 and $2.3 \AA$ at the CSA sites. A similar strong bonding at the CUS sites was reported for benzotriazole. ${ }^{8-10}$ Several other molecules were also found to bind significantly stronger at CUS sites than at coordinatively saturated sites. ${ }^{16,18,21}$

A comparison with the previous results, obtained on metallic $\mathrm{Cu}(111),{ }^{5}$ reveals that the bonding of imidazole, triazole, and tetrazole to CSA sites is similar in strength as their bonding to $\mathrm{Cu}(111)$. To facilitate the comprehension of trends, Fig. 3 compares adsorption energy magnitudes obtained on currently considered CSA and CUS sites to that on metallic $\mathrm{Cu}(111)$; the shown magnitudes refer to the most exothermic adsorption energies, regardless of the coverage. This figure clearly reveals that the bonding at CUS sites is considerably stronger than to $\mathrm{Cu}(111)$ and to $\mathrm{CSA}$ sites of $\mathrm{Cu}_{2} \mathrm{O}(111)-\mathrm{w} / \mathrm{o}-\mathrm{Cu}^{\mathrm{CUS}}$. Indeed, the bonding at the CUS sites is even stronger than, for example, the bonding of benzotriazole at very low coordinated surface defects on metallic $\mathrm{Cu}$ surfaces, which was calculated to be about $-1.3 \mathrm{eV} .^{32}$

A few more comments should be made with respect to the adsorption energy trends ( $c f$. Fig. 1-3). On $\mathrm{Cu}(111)$ the magnitude of adsorption energy, $\left|E_{\text {ads }}\right|$, decreases from imidazole to tetrazole at any coverage (for more details see ref. 5), whereas on $\mathrm{Cu}_{2} \mathrm{O}(111)-\mathrm{w} / \mathrm{o}-\mathrm{Cu}^{\mathrm{CUS}}$ the trends are bit more intricate due to the coverage dependence. At the lowest considered coverage, where the lateral dipolar intermolecular interactions are the smallest, the adsorption bonding strength follows the imidazole $\approx$ triazole $>$ tetrazole trend on both the CSA and CUS sites, ${ }^{* *}$ whereas at a larger coverage the trend is affected by lateral dipolar interactions. Considering the largest adsorption energy magnitudes ( $c f$. Fig. 3), irrespective of the coverage, the $\left|E_{\text {ads }}\right|$ trend at the CSA sites is imidazole $\approx$ triazole $\approx$ tetrazole, whereas at the CUS sites it is imidazole $<$ triazole $\lesssim$ tetrazole.

\subsection{Phase diagrams}

The coverage dependence of molecular adsorption energies, presented in Fig. 1 and 2, allows us to construct phase diagrams to ascertain which adsorbate structures are thermodynamically the most stable at a given molecular chemical potential, $\mu_{\mathrm{mol}}$. It should be noted that only three discrete coverages are considered using one molecule per $(N \times N)$ supercell, where $N \in[1,3]$. To provide better comprehension of how densely the molecules cover the surface at these coverages, Fig. 4 plots the top view snapshots of adsorbed triazole.

We first consider the adsorption surface free energy as a function of the molecular chemical potential ( $c f$. eqn (5)). The corresponding plots of $\gamma_{\text {ads }}$ for the current molecules are shown in the top row panels of Fig. 5, where the upper plots correspond to the adsorption at CSA and lower plots at CUS

** The reason that at a low coverage triazole bonds as strongly as imidazole to $\mathrm{Cu}_{2} \mathrm{O}(111)-w / o-C u^{\text {CUs }}$ is due to the hydrogen bonding effects (this issue will be further discussed in Section 3.3). 

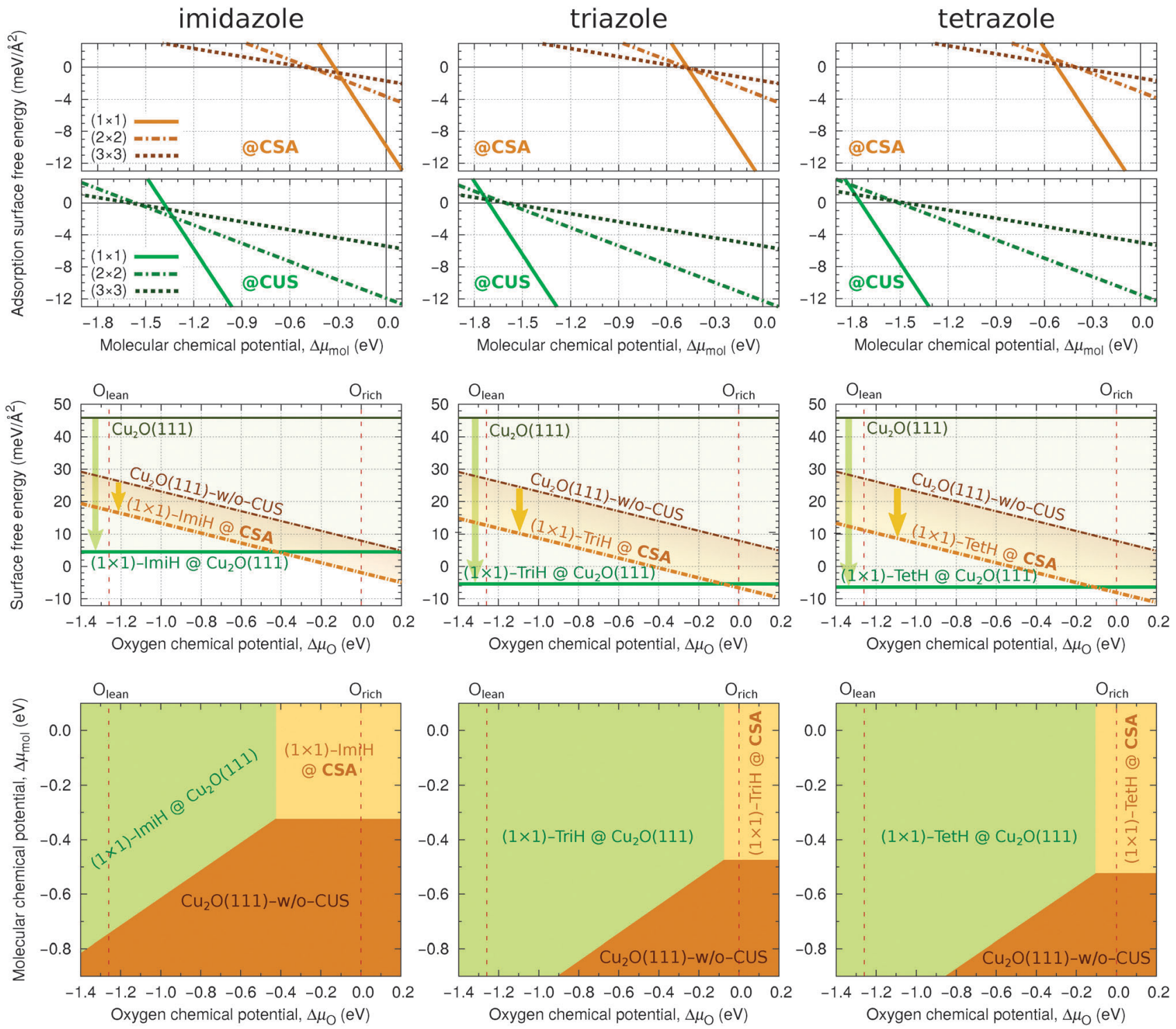

Fig. 5 Adsorption phase diagrams of imidazole (left), triazole (middle), and tetrazole (right) on considered $\mathrm{Cu}_{2} \mathrm{O}$ surfaces. Top row: Adsorption surface free energy, $\gamma_{\text {ads, }}$ as a function of the molecular chemical potential (CSA sites are considered in the upper panels and CUS sites in the bottom panels). Middle row: Surface free energies, $\gamma_{\text {surf, of }} \mathrm{Cu}_{2} \mathrm{O}(111)$ and $\mathrm{Cu}_{2} \mathrm{O}(111)-\mathrm{w} / \mathrm{o}-\mathrm{Cu}^{\mathrm{CUS}}$ and their stabilization due to high coverage molecular adsorption (for a given surface the upper $\gamma_{\text {surf }}$ line corresponds to a bare surface and the lower line to molecularly covered surface, while the vertical arrow indicates the stabilization due to high-coverage molecular adsorption). Bottom row: Two-dimensional phase diagrams as a function of molecular and oxygen chemical potentials. ImiH, TriH, and TetH stand for imidazole, triazole, and tetrazole, respectively, whereas " $1 \times 1)$-mol@CSA" is a shorthand label for $(1 \times 1)-m_{0 l} a_{C u} \mathrm{O}(111)-w / o-C u^{c u s}$, where $\mathrm{mol}$ is either $\mathrm{ImiH}$, TriH, or TetH.

sites. Thermodynamically the most stable structure at a given $\mu_{\mathrm{mol}}$ is the one that displays the lowest adsorption surface free energy. In these plots the black horizontal line at $\gamma_{\text {ads }}=$ $0.0 \mathrm{meV} \AA^{-2}$ corresponds to a clean surface, which is the most stable at a low $\mu_{\mathrm{mol}}$, before any of the molecular line intersects it. It should be noted that for a given molecule at a given coverage only the structure with the most exothermic adsorption energy is considered here. It can be seen that for tetrazole and in part triazole, which display attractive lateral interactions, the high-coverage phases are always the most stable, unless the $\mu_{\mathrm{mol}}$ is so low that the bare surfaces become the most stable. In addition, for triazole at the CSA sites, the lower coverage phases are competitive with the high-coverage phase around $\Delta \mu_{\mathrm{mol}} \approx-0.5 \mathrm{eV}$, where their $\gamma_{\text {ads }}$ lines intersect the clean surface line. In contrast, the situation is different for imidazole, because it displays repulsive lateral interactions. At the CSA sites, the highcoverage $(1 \times 1)$ phase is the most stable at $\Delta \mu_{\mathrm{mol}}>-0.27 \mathrm{eV}$. Below this value the lower coverage phases are the most stable, first the $(2 \times 2)$ and then the $(3 \times 3)$, but only down to $\Delta \mu_{\mathrm{mol}}=$ $-0.51 \mathrm{eV}$, where the clean surface becomes the most stable. Note that only a few discrete coverages are considered in Fig. 5, hence there can be intermediate situations, but the point is that one passes from low- to high-coverage imidazole structures as the $\mu_{\mathrm{mol}}$ increases from $-0.51 \mathrm{eV}$ to $-0.27 \mathrm{eV}$. A similar relationship 
between high and lower coverage phases of imidazole also exists at the CUS sites with the exception that the stability intercepts are shifted to the left by about $1 \mathrm{eV}$ due to much stronger molecular bonding at CUS compared to CSA sites. $\dagger \dagger$

It should be noted that for the high-coverage $(1 \times 1)$ adsorption phases the number of adsorbed molecules equals to the number of CUS sites on stoichiometric $\mathrm{Cu}_{2} \mathrm{O}(111)$, which implies that $(1 \times 1)$ molecular phases at CUS sites correspond to molecular adsorption on stoichiometric $\mathrm{Cu}_{2} \mathrm{O}(111)$. Given that the high-coverage $(1 \times 1)$ molecular phases dominate in the $\gamma_{\text {ads }}\left(\mu_{\text {mol }}\right)$ phase diagrams and the molecules bind much strongly to CUS than to CSA sites, opens a question whether this bonding enhancement is sufficient to stabilize the stoichiometric $\mathrm{Cu}_{2} \mathrm{O}(111)$ surface with respect to $\mathrm{Cu}_{2} \mathrm{O}(111)-w / 0-\mathrm{Cu}^{\text {Cus }}$. This issue is addressed in the middle row panels of Fig. 5, which show how the high-coverage $(1 \times 1)$ molecular phases stabilize the surface free energies of $\mathrm{Cu}_{2} \mathrm{O}(111)-w / o-\mathrm{Cu}^{\mathrm{CUS}}$ and stoichiometric $\mathrm{Cu}_{2} \mathrm{O}(111)$ ( $c f$. eqn (6)). It is apparent that the stabilization of stoichiometric $\mathrm{Cu}_{2} \mathrm{O}(111)$ due to adsorption of triazole and tetrazole is so large that the $(1 \times 1)$ molecularly covered $\mathrm{Cu}_{2} \mathrm{O}(111)$ dominates in the respective phase diagrams (horizontal thick green line). Only near the oxygen-rich limit, $\Delta \mu_{\mathrm{O}} \gtrsim-0.1 \mathrm{eV}$, the triazole and tetrazole covered $\mathrm{Cu}_{2} \mathrm{O}(111)-\mathrm{w} /$ $\mathrm{o}^{-\mathrm{Cu}^{\mathrm{CUS}}}$ become competitive. For imidazole the stabilization of stoichiometric $\mathrm{Cu}_{2} \mathrm{O}(111)$ is less pronounced and imidazole covered $\mathrm{Cu}_{2} \mathrm{O}(111)-w / 0-C u^{\text {CUS }}$ remains the most stable for $\Delta \mu_{\mathrm{O}} \gtrsim-0.4 \mathrm{eV}$, which represents about $30 \%$ span of the range between oxygen-lean and oxygen-rich limits of $\mu_{\mathrm{O}}$.

The above one-dimensional treatments can be extended by considering the adsorption surface free energy as a twodimensional function of $\mu_{\mathrm{mol}}$ and $\mu_{\mathrm{O}}$ via eqn (8). The bottom row panels of Fig. 5 show the resulting two-dimensional phase diagrams. These phase diagrams show only the most stable structures at agiven $\left(\mu_{\mathrm{mol}}, \mu_{\mathrm{O}}\right)$. Regardless of the molecule, only three structures appear in the phase diagrams: (i) high coverage $(1 \times 1)$ molecular phase on stoichiometric $\mathrm{Cu}_{2} \mathrm{O}(111)$ in the top left region, (ii) high coverage $(1 \times 1)$ molecular phase on $\mathrm{Cu}_{2} \mathrm{O}(111)$ w/o- $\mathrm{Cu}^{\mathrm{CUS}}$ in the top right region, and (iii) bare $\mathrm{Cu}_{2} \mathrm{O}(111)-\mathrm{w} / \mathrm{o}-$ $\mathrm{Cu}^{\mathrm{CUS}}$ in the bottom right region. For triazole and tetrazole, the phase diagrams are dominated by the $(1 \times 1)-\mathrm{mol} @ \mathrm{Cu}_{2} \mathrm{O}(111)$ structure, whereas $(1 \times 1)-\mathrm{mol} @ \mathrm{Cu}_{2} \mathrm{O}(111)-\mathrm{w} / \mathrm{o}-\mathrm{Cu}^{\mathrm{CUS}}$ exists only around the oxygen-rich limit when $\Delta \mu_{\mathrm{mol}} \gtrsim-0.5 \mathrm{eV}$. Even for imidazole, which displays repulsive lateral interactions, only the high-coverage $(1 \times 1)$ molecular phases appear in the phase diagram, but their stability region is significantly reduced in favor of bare $\mathrm{Cu}_{2} \mathrm{O}(111)-\mathrm{w} / \mathrm{o}-\mathrm{Cu}{ }^{\mathrm{Cus}}$, i.e., the stability borders are shifted up-left compared to that of triazole or tetrazole.

Finally let us make a rather crude estimate, using the idealgas approximation, to which the $\Delta \mu_{\mathrm{O}}$ and $\Delta \mu_{\text {mol }}$ values would correspond at room temperature and partial pressure of $p=1$ atm; the corresponding calculated values are $\Delta \mu_{\mathrm{O}} \approx-0.3 \mathrm{eV}$

$\dagger \dagger$ For imidazole at the CUS site the high coverage $(1 \times 1)$ phase is the most stable at $\Delta \mu_{\text {mol }}>-1.33 \mathrm{eV}$. Below this value the $(2 \times 2)$ phase is the most stable and near its intercept with the clean surface line at $\Delta \mu_{\mathrm{mol}} \approx-1.6 \mathrm{eV}$ also the low coverage $(3 \times 3)$ phase becomes competitive. and $\Delta \mu_{\mathrm{mol}} \approx-0.7 \mathrm{eV}$. $\neq$ At these $\Delta \mu_{\mathrm{O}}$ and $\Delta \mu_{\mathrm{mol}}$ values the $\mathrm{Cu}_{2} \mathrm{O}(111)-\mathrm{w} / \mathrm{o}-\mathrm{Cu}^{\text {CUS }}$ phase is the most stable for imidazole, but for triazole and tetrazole this point lies close to the border with the $(1 \times 1)$-mol@ $\mathrm{Cu}_{2} \mathrm{O}(111)$ phase, which would prevail under more oxygen lean conditions. It is worth remarking that when van der Waals dispersion correction is taken into account, which enhances the molecular adsorption bonding (see Section 3.4), then the $\left(\Delta \mu_{\mathrm{O}}, \Delta \mu_{\mathrm{mol}}\right)=(-0.3 \mathrm{eV},-0.7 \mathrm{eV})$ point lies deep inside the region of high coverage molecular phases [either $(1 \times 1)$-mol@ $\mathrm{Cu}_{2} \mathrm{O}(111)-\mathrm{w} / \mathrm{o}-\mathrm{Cu}^{\text {CUS }}$ or $\left.(1 \times 1)-\mathrm{mol} @ \mathrm{Cu}_{2} \mathrm{O}(111)\right]$.

\subsection{Electronic structure analysis}

To gain more insight into the chemistry of the molecule-surface bonding, Fig. 6 displays the charge density difference, $\Delta \rho(\mathbf{r})$, for imidazole, triazole, and tetrazole bound to the CSA (top row) and CUS (bottom row) sites. Only the most stable adsorption structures at a low coverage are considered, i.e., $\mathrm{N} 3+\mathrm{C} 2 \mathrm{H} \cdots \mathrm{O}^{\text {up }}$ for imidazole and $\mathrm{N} 2+\mathrm{N} 1 \mathrm{H} \cdots \mathrm{O}^{\text {up }}$ for triazole $\S$ and tetrazole. In the $\Delta \rho(\mathbf{r})$ plots, the red color represents electron charge accumulation and the blue color represents electron deficit regions. The formation of direct $\mathrm{N}-\mathrm{Cu}$ bonds is clearly seen by the red colored charge accumulation lobes in the midst of these bonds. These electron charge accumulation lobes are weak at the CSA sites and much stronger at the CUS sites, which readily explains the much stronger molecular bonding at the latter. In addition to the $\mathrm{N}-\mathrm{Cu}$ bonds, the molecules also interact at the surface with the $\mathrm{X}-\mathrm{H} \cdots \mathrm{O}^{\text {up }}$ hydrogen bonds $(\mathrm{X}=\mathrm{C} 2$ for imidazole or $\mathrm{N} 1$ for triazole and tetrazole). These $\mathrm{H}$-bonds are characterized by the substantial charge accumulation located above the pertinent $\mathrm{O}^{\text {up }}$ ion and the charge deficit region of the nearby $\mathrm{H}$ atom. The intensities of these charge redistributions clearly reveal that the $\mathrm{N}-\mathrm{H} \cdots \mathrm{O}$ bonds of triazole and tetrazole are considerably stronger than the $\mathrm{C}-\mathrm{H}$. . O bonds of imidazole. For further characterization of the strength of $\mathrm{N}-\mathrm{H} \cdots \mathrm{O}$ and $\mathrm{C}-\mathrm{H} \cdots \mathrm{O}$ bonds see Fig. S2 in the ESI. $\dagger$ The $\Delta \rho(\mathbf{r})$ plots reveal that the strength of $\mathrm{N}-\mathrm{Cu}$ bonds increases from tetrazole to imidazole (at the CSA sites), but the strength of the $\mathrm{X}-\mathrm{H} \cdots \mathrm{O}$ hydrogen bonds follows the opposite direction, i.e., imidazole $<$ triazole $\lesssim$ tetrazole (at both the CSA and CUS sites). $\uparrow$ The latter is the reason that at a low coverage, where the lateral dipolar interactions are sufficiently small, the bonding

$\ddagger \ddagger$ These values were calculated with the thermochemistry utility of the Gaussian 09 program package. ${ }^{48}$

$\S \S$ It should be noted that for triazole at the CSA site, $\mathrm{N} 2+\mathrm{N} 1 \mathrm{H} \cdots \mathrm{O}_{\mathrm{far}}^{\mathrm{up}}$ is marginally more stable at a low coverage than the considered $\mathrm{N} 2+\mathrm{N} 1 \mathrm{H} \cdots \mathrm{O}_{\text {near }}^{\text {up }}$ (see Fig. 1), but the difference is insignificant.

Фब The $\Delta \rho(\mathbf{r})$ plots clearly reveal that at the CSA site the strength of the $\mathrm{N}-\mathrm{Cu}$ bond decreases from imidazole to tetrazole, which is consistent with the increasing $\mathrm{N}-\mathrm{Cu}$ bond length in the same direction. In contrast, at the CUS site the $\mathrm{N}-\mathrm{Cu}$ electron charge accumulation lobes as well as the $\mathrm{N}-\mathrm{Cu}$ bond lengths appear to be very similar for all the three molecules. This suggests that at a low coverage the molecule-surface interaction should be the weakest for imidazole, because it lacks the strong $\mathrm{N}-\mathrm{H} \cdots \mathrm{O}$ hydrogen bond. But this is not the case. The reason can be attributed to molecular chemical hardness, which increases from imidazole to tetrazole. ${ }^{5,6}$ Namely, at the CUS site the molecular electronic structure is sufficiently perturbed due to a strong molecule-surface interaction and the hybridization between molecular and copper states is the easiest for imidazole, which is chemically the softest among the three molecules. 

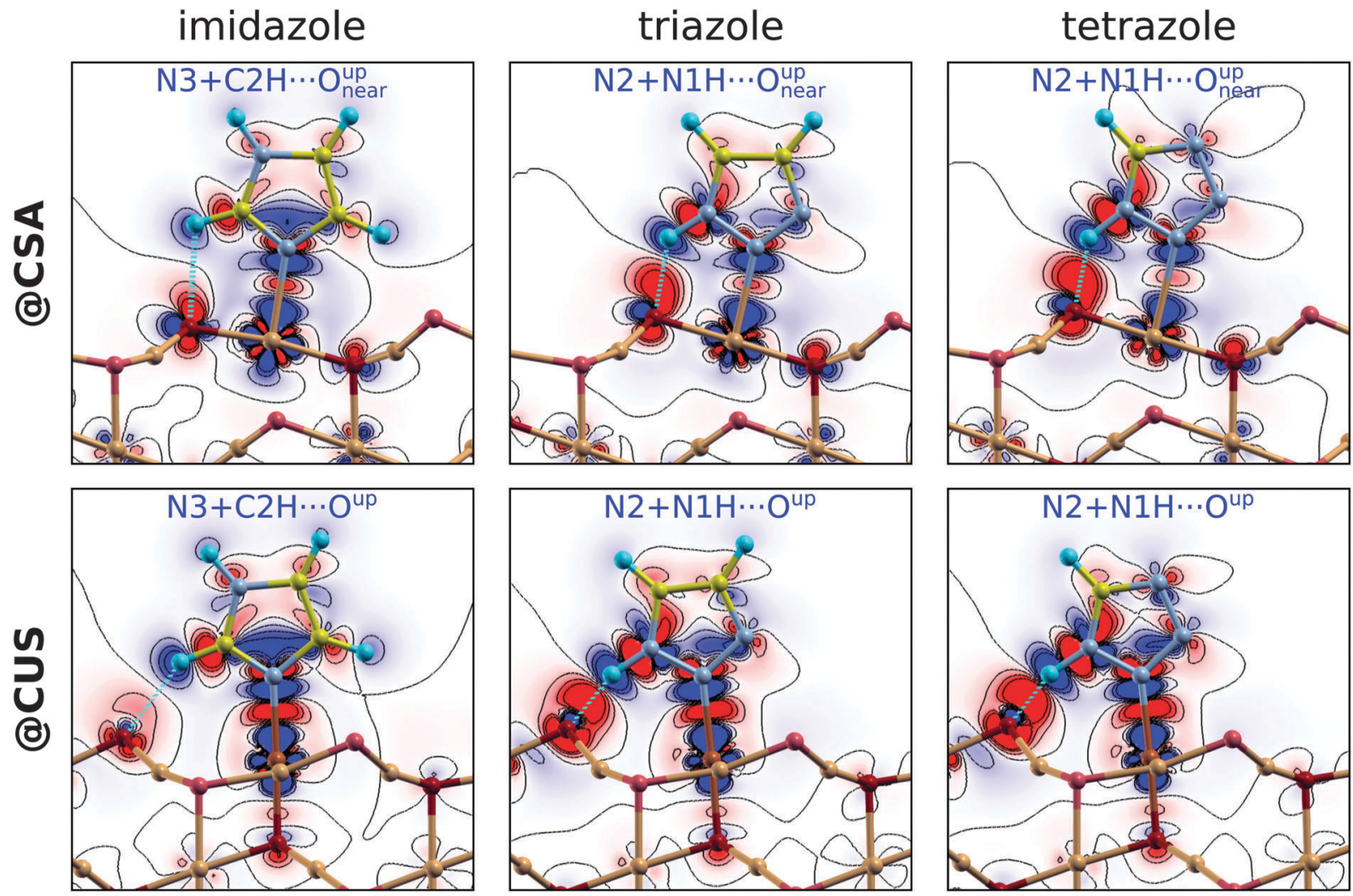

Fig. 6 Electron charge density difference, $\Delta \rho(\mathbf{r})$, for imidazole, triazole, and tetrazole bonded at CSA (top) and CUS (bottom) sites. The plots are drawn with seven contours in a linear scale from -0.006 to $+0.006 \mathrm{e} \mathrm{a}_{0}^{-3}$. The blue (red) color represents the electron deficit (excess) regions, i.e., electron charge flows from blue to red regions.

strengths of imidazole and triazole are almost degenerate, but the bonding strength of tetrazole is about $0.1 \mathrm{eV}$ less. The stronger $\mathrm{N}-\mathrm{H} \cdots \mathrm{O}$ bond compared to the $\mathrm{C}-\mathrm{H} \cdots \mathrm{O}$ bond is therefore able to compensate for the weaker $\mathrm{N}-\mathrm{Cu}$ bond of triazole compared to that of imidazole, but falls somewhat short for compensating the even weaker $\mathrm{N}-\mathrm{Cu}$ bond of tetrazole.

A further analysis of the three-dimensional shape of $\Delta \rho(\mathbf{r})$ (not shown) reveals that the molecules interact with the surface through $\sigma$-type bonding, which is expected on the basis of the local symmetry of the $\mathrm{N}-\mathrm{Cu}$ bonds. Even finer details of the molecule-surface interaction are provided for triazole in Fig. 7, where the same adsorption structure as in the $\Delta \rho(\mathbf{r})$ plot is considered, i.e., the $\mathrm{N} 2+\mathrm{N} 1 \mathrm{H} \cdots \mathrm{O}^{\text {up }}$ at the CSA and CUS sites. This figure displays the density of states projected (PDOS) to the molecule and the $\mathrm{Cu}$ atom beneath it, before and after the molecule-surface interaction sets in. These two cases will be termed before-interaction and after-interaction; for the former case, the molecule is up-shifted such that the $\mathrm{N}-\mathrm{Cu}$ distance is $6 \AA$ A. In addition, the figure also shows the integrated local density of states (ILDOS) analysis as well as the density of states projected to individual molecular orbitals (MO-PDOS) ${ }^{49}$ of triazole, because these two techniques allow for unambiguous assignment of molecular PDOS peaks to individual molecular orbitals (MOs).

The before-interaction PDOS plots reveal that four molecular orbitals (from HOMO-3 to HOMO (highest-occupied MO)) lie at the position of the metal d-band and are therefore considered in the analysis of the molecule-surface bonding; the LUMO (lowest-unoccupied MO) state, which lies more than $3 \mathrm{eV}$ above the valence band edge, is also considered. Two among these MOs are $\sigma$-type orbitals (HOMO- 3 and HOMO) and three are $\pi$-type orbitals (HOMO-2, HOMO-1, and LUMO). Upon interaction these molecular states downshift in energy. The downshift is larger and the molecular PDOS is more broadened for the CUS sites in accordance with the stronger moleculesurface interaction at the CUS compared to that at the CSA site. The downshift is the largest for the HOMO-3 $\sigma$-orbital, being about $2 \mathrm{eV}$ at the CSA sites and about $3 \mathrm{eV}$ at the CUS sites, and its PDOS peaks are the most broadened. These PDOS peaks are located at around $-5 \mathrm{eV}$ for the CSA sites and at around $-6 \mathrm{eV}$ for the CUS sites. The ILDOS analysis clearly reveals that only these low lying molecular peaks are involved in the interaction with the copper states, \|\| whereas all the other molecular peaks are non-bonding with respect to the molecule-surface interaction. The MO-PDOS plots show that, in addition to HOMO-3, also the HOMO orbital marginally participates in the bonding low-lying peaks, but its

|| || It should be noted that the ILDOS analysis shows only four plots per site, although five MOs are considered. The reason is that the HOMO-1 and HOMO states are located in the same energy region and cannot be separated, i.e., their PDOS peaks overlap, which is also evident from the respective MO-PDOS plots. 


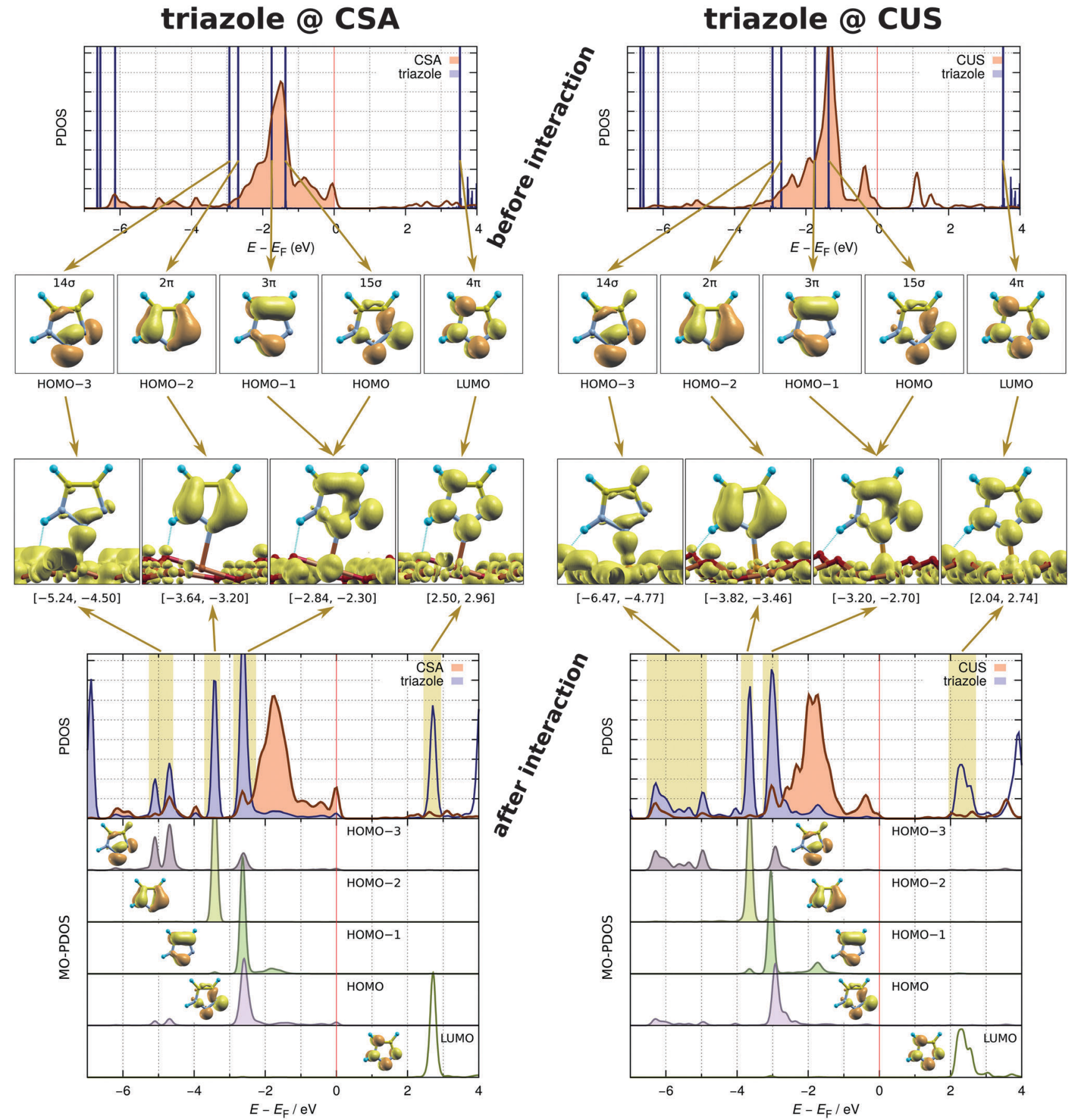

Fig. 7 Bonding analysis of triazole at the CSA (left) and CUS (right) sites. From top to bottom: (1) density of states projected (PDOS) to the molecule (blue) and the $\mathrm{Cu}$ atom beneath it (brown) before the interaction sets in (i.e., the molecule is $\sim 6 \AA$ above the surface). (2) Signed square modulus of molecular orbitals, i.e., $\operatorname{sgn}[\phi(\mathbf{r})] \times|\phi(\mathbf{r})|^{2}$. (3) Integrated local density of states (ILDOS) of the interacting molecule/surface system; the integrated energy ranges are stated below the ILDOS plots and are also indicated by pale vertical bands beneath. (4) PDOS plots of the interacting molecule/surface system; below the PDOS plots the density of states is projected to individual molecular orbitals (MO-PDOS).

predominant contribution is in the uppermost valence (occupied) molecular PDOS peak located at about $-2.5 \mathrm{eV}$ at the CSA sites and at about $-3 \mathrm{eV}$ at the CUS sites. The MO-PDOS plots further reveal that there is no back-donation of charge from the surface into the molecular LUMO, because the LUMO remains completely empty upon interaction, that is, the MO-PDOS shows no participation of the LUMO in the molecule-surface valence states.

\subsection{Dispersion corrections}

The results presented in the preceding Sections 3.1-3.3 were obtained using the PBE energy functional, which cannot describe 
Table 1 Comparison of PBE and PBE-D" adsorption energies for high coverage $(1 \times 1)$ adsorption phases. Only the most stable adsorption mode is considered at the CUS sites, whereas for the CSA sites two modes are considered, because dispersion correction alters the relative stability of modes in some cases (the most stable adsorption energies are emphasized in bold). The label $\Delta$ stands for the difference between the PBE-D" and PBE adsorption energies for a given mode, whereas $\Delta_{\text {best }}$ is the difference between the most stable PBE and the most stable PBE- $D^{\prime \prime}$ adsorption modes for a given molecule, i.e., the difference between the two energies written in bold

\begin{tabular}{|c|c|c|c|c|c|c|c|}
\hline & & & Adsorption structure & \multicolumn{2}{|c|}{$\underline{E_{\text {ads }}(\mathrm{eV})}$} & \multicolumn{2}{|c|}{ PBE-D ${ }^{\prime \prime}-\mathrm{PBE}$} \\
\hline$(1 \times 1)-\mathrm{mol} @ \mathrm{Cu}_{2} \mathrm{O}(111)-\mathrm{w} / \mathrm{o}-\mathrm{Cu}^{\mathrm{CUS}}$ & CSA & Imidazole & $\begin{array}{l}\mathrm{N} 3+\mathrm{C} 2 \mathrm{H} \cdots \mathrm{O}_{\text {near }}^{\text {up }} \\
\mathrm{N} 3+\mathrm{C} 2 \mathrm{H} \cdots \mathrm{O}^{\text {sub }}\end{array}$ & $\begin{array}{l}-0.15 \\
-0.32\end{array}$ & $\begin{array}{l}-0.43 \\
-\mathbf{0 . 8 5}\end{array}$ & $\begin{array}{l}-0.28 \\
-0.53\end{array}$ & -0.53 \\
\hline & & Triazole & $\begin{array}{l}\mathrm{N} 2+\mathrm{N} 1 \mathrm{H} \cdots \mathrm{O}_{\text {near }}^{\text {up }} \\
\mathrm{N} 2+\mathrm{N} 1 \mathrm{H} \cdots \mathrm{O}^{\text {sub }}\end{array}$ & $\begin{array}{l}-0.47 \\
-0.46\end{array}$ & $\begin{array}{l}-0.71 \\
-0.98\end{array}$ & $\begin{array}{l}-0.24 \\
-0.52\end{array}$ & -0.51 \\
\hline & & Tetrazole & $\begin{array}{l}\mathrm{N} 2+\mathrm{N} 1 \mathrm{H} \cdots \mathrm{O}_{\text {near }}^{\text {up }} \\
\mathrm{N} 2+\mathrm{N} 1 \mathrm{H} \cdots \mathrm{O}^{\text {sub }}\end{array}$ & $\begin{array}{l}-0.52 \\
-0.33\end{array}$ & $\begin{array}{l}-0.75 \\
-\mathbf{0 . 8 2}\end{array}$ & $\begin{array}{l}-0.23 \\
-0.49\end{array}$ & -0.30 \\
\hline$(1 \times 1)-m o l @ \mathrm{Cu}_{2} \mathrm{O}(111)$ & $\operatorname{CUS}^{a}$ & $\begin{array}{l}\text { Imidazole } \\
\text { Triazole } \\
\text { Tetrazole }\end{array}$ & $\begin{array}{l}\mathrm{N} 3+\mathrm{C} 2 \mathrm{H} \cdots \mathrm{O}^{\text {up }} \\
\mathrm{N} 2+\mathrm{N} 1 \mathrm{H} \cdots \mathrm{O}^{\text {up }} \\
\mathrm{N} 2+\mathrm{N} 1 \mathrm{H} \cdots \mathrm{O}^{\text {up }}\end{array}$ & $\begin{array}{l}-1.39 \\
-1.71 \\
-1.75\end{array}$ & $\begin{array}{l}-1.74 \\
-2.02 \\
-2.04\end{array}$ & $\begin{array}{l}-0.35 \\
-0.31 \\
-0.29\end{array}$ & \\
\hline
\end{tabular}

van der Waals dispersion interactions. To shed some light onto how dispersion interactions affect the adsorption characteristics, they were estimated for the high coverage $(1 \times 1)$ adsorption phases and are presented in Table 1 , which compares the corresponding PBE and dispersion corrected PBE-D" adsorption energies. In the following text the adsorbed molecules that form the hydrogen bond with $\mathrm{O}^{\text {up }}$ or $\mathrm{O}_{\text {near }}^{\text {up }}$ ions are referred as $\mathrm{O}^{\text {up }}$ modes and the molecules that form the hydrogen bond with $\mathrm{O}^{\text {sub }}$ ions as $\mathrm{O}^{\text {sub }}$ adsorption modes. Dispersion correction enhances the molecular adsorption bonding by about $0.3 \mathrm{eV}$ for the $\mathrm{O}^{\text {up }}$ and about $0.5 \mathrm{eV}$ for the $\mathrm{O}^{\text {sub }}$ adsorption modes for all the three molecules; the $\mathrm{N}-\mathrm{Cu}$ bonds correspondingly shorten by about 0.05 and $0.01 \AA$ at the CSA and CUS sites, respectively. The reason that the $\mathrm{O}^{\text {sub }}$ adsorption modes are stabilized stronger by dispersion interactions than the $\mathrm{O}^{\text {up }}$ modes is that for the former molecules are located closer to the surface than for the latter, because they are tilted into the $\mathrm{Cu}^{\mathrm{Cus}}$ vacancies (see the respective snapshots in Fig. 1). Due to this stronger stabilization of the $\mathrm{O}^{\text {sub }}$ adsorption modes, the relative stability of modes is altered for tetrazole at the CSA sites, i.e., without dispersion correction the $\mathrm{O}^{\text {up }}$ adsorption mode is by $0.2 \mathrm{eV}$ more stable than the $\mathrm{O}^{\text {sub }}$ adsorption mode (note that for triazole the two modes are almost degenerate, while for imidazole the $\mathrm{O}^{\text {sub }}$ mode is more stable). But when dispersion correction is taken into account, the $\mathrm{O}^{\text {sub }}$ adsorption modes are the most stable at the CSA sites for all the three molecules. The net stabilization due to dispersion interactions at the CSA sites-calculated as the difference between the most stable PBE and PBE- $\mathrm{D}^{\prime \prime}$ adsorption modes-is therefore stronger for imidazole and triazole (about $0.5 \mathrm{eV}$ ) than for tetrazole $(0.3 \mathrm{eV})$; see the $\Delta_{\text {best }}$ column in Table 1 . In contrast, at the CUS sites, which lacks the $\mathrm{O}^{\text {sub }}$ adsorption modes, the stabilization is only about $0.3 \mathrm{eV}$ for all the three molecules.

Dispersion interactions stabilize the adsorption structures mainly through the enhanced molecule-surface bonding. However, for the high-coverage phases the dispersion forces also affect the lateral molecule-molecule interactions due to proximity of neighboring molecules. The lateral molecule-molecule dispersion interactions were estimated ${ }^{* *}$ only for imidazole at the CSA and CUS sites and amount to $-0.04 \mathrm{eV}$ per molecule for both sites. Given the empirical nature of the utilized dispersion correction, it can be straightforwardly inferred that it gives slightly weaker lateral molecule-molecule dispersion interactions for triazole and tetrazole compared to imidazole, because an $\mathrm{N}$ atom has a smaller $C_{6}$ coefficient than a $\mathrm{C}$ atom. The current results therefore imply that the lateral molecule-molecule dispersion interactions contribute about $10 \%$ to the overall dispersion enhancement of the adsorption energy at the high coverage.

Dispersion corrections affect the adsorption phase-diagrams of Fig. 5 in two ways: (i) the enhancement of the adsorption energy downshifts the borders between the $(1 \times 1)$ adsorption phases and bare $\mathrm{Cu}_{2} \mathrm{O}(111)-\mathrm{w} / \mathrm{o}-\mathrm{Cu}^{\mathrm{CUS}}$, i.e., the brown region in Fig. 5 is displaced to lower values of $\mu_{\text {mol }}$. (ii) For imidazole and

*** Lateral molecule-molecule dispersion interactions $\left(E_{\text {disp }}^{\text {lateral }}\right)$ were estimated, by performing a set of single-point calculations, as follows:

$$
E_{\text {disp }}^{\text {lateral }}=E_{\text {lateral }}^{\mathrm{PBE}}-E_{\text {lateral }}^{\mathrm{PBE}}
$$

and

$$
E_{\text {lateral }}=E_{\mathrm{mol}}^{(1 \times 1)}-E_{\mathrm{mol}}
$$

where $E_{\text {lateral }}$ is calculated with both the $\mathrm{PBE}-\mathrm{D}^{\prime \prime}\left(E_{\text {lateral }}^{\mathrm{PBE}-\mathrm{D}^{\prime \prime}}\right)$ and $\mathrm{PBE}\left(E_{\text {lateral }}^{\mathrm{PBE}}\right)$ functionals. $E_{\mathrm{mol}}^{(1 \times 1)}$ is the total energy of the $(1 \times 1)$ layer of molecules with structure kept the same as in the adsorption system and $E_{\text {mol }}$ is the total energy of the isolated molecule having the same structure as the molecule in the $(1 \times 1)$ layer. The reason that the lateral molecule-molecule dispersion interactions are calculated by eqn (11) and not simply by $E_{\text {lateral }}^{\mathrm{PBE}-\mathrm{D}}$ of eqn (12) is due to a large permanent molecular dipole moment of azoles. Hence the $E_{\text {lateral }}^{\mathrm{PBE}} \mathrm{D}^{\prime \prime}$ also contains the lateral dipole-dipole contributions, which are canceled out by the $E_{\text {lateral }}^{\mathrm{PBE}}$ term in eqn (11). 
triazole the border between $(1 \times 1)$-mol@ $\mathrm{Cu}_{2} \mathrm{O}(111)$ [green region] and $(1 \times 1)$-mol@CSA [yellow region] shifts to the left, i.e., to lower values of $\mu_{\mathrm{O}}$, because the dispersion bonding enhancement is larger at the CSA sites $(\approx 0.5 \mathrm{eV})$ than at the CUS $(\approx 0.3 \mathrm{eV})$ sites. In contrast, for tetrazole the dispersion bonding enhancement is almost the same at the two sites and the pertinent border remains unaffected. The resulting, dispersion corrected phase diagrams are presented in Fig. S3 in the ESI. $\dagger$

Finally, some caution is in place concerning the currently used semi-empirical dispersion correction. Namely, PBE-D was currently reparametrized $\left(\mathrm{PBE}-\mathrm{D}^{\prime \prime}\right)$ to match the experimental adsorption energy of flat lying benzene on $\mathrm{Cu}(111)$, because the original PBE-D often overestimates the molecule-surface bonding. ${ }^{27,29,30,50}$ However, the current adsorption systems consist of $\mathrm{Cu}_{2} \mathrm{O}$ oxide surfaces and molecules that bond perpendicularly or tilted to the surface. For this reason the current dispersion corrected results may be taken more qualitatively than quantitatively.

\section{Conclusions}

Adsorption bonding of imidazole, triazole, and tetrazole to $\mathrm{Cu}_{2} \mathrm{O}(111)-\mathrm{w} / \mathrm{o}-\mathrm{Cu}^{\mathrm{CUS}}$ and $\mathrm{Cu}_{2} \mathrm{O}(111)$ was characterized by means of DFT calculations. The difference between these two surfaces is that the $\mathrm{Cu}_{2} \mathrm{O}(111)-\mathrm{w} / \mathrm{o}-\mathrm{Cu}^{\mathrm{CUS}}$ lacks the reactive CUS sites and is consequently thermodynamically more stable than $\mathrm{Cu}_{2} \mathrm{O}(111)$. We showed that the bonding of current azole molecules at CUS sites on $\mathrm{Cu}_{2} \mathrm{O}(111)$ is by about $1 \mathrm{eV}$ stronger than at CSA sites on $\mathrm{Cu}_{2} \mathrm{O}(111)-\mathrm{w} / \mathrm{o}-\mathrm{Cu}^{\mathrm{CUS}}$. The bonding at CUS sites is so strong that it compensates the thermodynamic deficiency of $\mathrm{Cu}_{2} \mathrm{O}(111)$, making it more stable than $\mathrm{Cu}_{2} \mathrm{O}(111)-\mathrm{w} / \mathrm{o}-\mathrm{Cu}^{\mathrm{CUS}}$, provided the conditions are not too oxygen rich and/or azole lean. This finding, together with the previously observed trend that azoles bond significantly stronger to low coordinated defects on metallic $\mathrm{Cu}$ surfaces than to high coordinated flat facets, ${ }^{32,33}$ indicates that azoles have a strong affinity to preferentially adsorb at reactive undercoordinated or unsaturated surface sites, which in turn tentatively suggests that their corrosion inhibition capability may, at least in part, stem from their ability to passivate reactive surface sites.

As for the chemical nature of the molecule-surface interaction, we showed that the current azole molecules preferentially bind to $\mathrm{Cu}_{2} \mathrm{O}$ surfaces via a single $\sigma$-type $\mathrm{N}-\mathrm{Cu}$ bond and concomitantly form a hydrogen bond with a nearby surface $\mathrm{O}$ ion. Adsorption bonding is further enhanced by van der Waals dispersion interactions, in the range $0.23-0.53 \mathrm{eV}$, depending on specifics of the adsorption structure. This is a sizable enhancement, because it represents about $50-60 \%$ of the total adsorption bonding at the CSA and about $15-20 \%$ at CUS sites. At large intermolecular separations (or at a low coverage), where the lateral dipole-dipole effects are sufficiently small, the magnitude of adsorption energy follows the imidazole $\approx$ triazole $>$ tetrazole order, but at a high coverage the trend is altered, because imidazole displays repulsive and tetrazole attractive lateral dipole-dipole interactions. Despite these differences in lateral interactions, atomistic thermodynamics analysis reveals that for all the three molecules only three among the considered phases appear in the phase diagrams: high coverage $(1 \times 1)$ mol@ $\mathrm{Cu}_{2} \mathrm{O}(111)$ and $(1 \times 1)-\mathrm{mol} @ \mathrm{Cu}_{2} \mathrm{O}(111)-\mathrm{w} / \mathrm{o}-\mathrm{Cu}^{\mathrm{CUS}}$ molecular phases, and clean $\mathrm{Cu}_{2} \mathrm{O}(111)-\mathrm{w} / \mathrm{o}-\mathrm{Cu}^{\mathrm{CUS}}$.

\section{Acknowledgements}

This work has been supported by the Slovenian Research Agency (Grant No. P2-0148 and P2-0393).

\section{References}

1 Y. I. Kuznetsov and L. P. Kazansky, Russ. Chem. Rev., 2008, 77, 219-232.

2 M. M. Antonijević, S. M. Milić and M. B. Petrović, Corros. Sci., 2009, 51, 1228-1237.

3 J. O. Bockris and A. K. N. Reddy, Modern Electrochemistry, Kluwer Academic/Plenum Publishers, New York, Boston, Dordrecht, London, Moscow, 2nd edn, 2000, vol. 2B.

4 C. D. Taylor, A. Chandra, J. Vera and N. Sridhar, Faraday Discuss., 2015, 180, 459-477.

5 N. Kovačević and A. Kokalj, J. Phys. Chem. C, 2011, 115, 24189-24197.

6 N. Kovačević and A. Kokalj, Corros. Sci., 2013, 73, 7-17.

7 M. Pourbaix, Atlas of Electrochemical Equilibria in Aqueous Solutions, NACE, Cebelcor, Houston, Texas, 2nd edn, 1974.

8 Y. Jiang, J. B. Adams and D. Sun, J. Phys. Chem. B, 2004, 108, 12851-12857.

9 A. Kokalj and S. Peljhan, J. Phys. Chem. C, 2015, 119, 11625-11635.

10 A. Kokalj, Faraday Discuss., 2015, 180, 415-438.

11 O. Blajiev and A. Hubin, Electrochim. Acta, 2004, 49, 2761-2770.

12 T. Bredow and G. Pacchioni, Surf. Sci., 1997, 373, 21-32.

13 M. Casarin and A. Vittadini, Surf. Sci., 1997, 387, L1079-L1084.

14 M. Casarin, C. Maccato, N. Vigato and A. Vittadini, Appl. Surf. Sci., 1999, 142, 164-168.

15 A. Soon, T. Söhnel and H. Idriss, Surf. Sci., 2005, 579, 131-140.

16 M. Li, J.-y. Zhang, Y. Zhang, G.-f. Zhang and T.-m. Wang, Appl. Surf. Sci., 2011, 257, 10710-10714.

17 H. Wu, N. Zhang, H. Wang and S. Hong, Chem. Phys. Lett., 2013, 568-569, 84-89.

18 L. I. Bendavid and E. A. Carter, J. Phys. Chem. C, 2013, 117, 26048-26059.

19 Y. Shen, F. H. Tian, S. Chen, Z. Ma, L. Zhao and X. Jia, Appl. Surf. Sci., 2014, 288, 452-457.

20 M. Altarawneh, M. W. Radny, P. V. Smith, J. C. Mackie, E. M. Kennedy, B. Z. Dlugogorski, A. Soon and C. Stampfl, Appl. Surf. Sci., 2010, 256, 4764-4770.

21 I. C. Man, S. G. Soriga and V. Pârvulescu, Chem. Phys. Lett., 2014, 604, 38-45.

22 Z. Wang, X. Liu, D. Rooney and P. Hu, Surf. Sci., 2015, 640, 181-189. 
23 A. Soon, M. Todorova, B. Delley and C. Stampfl, Phys. Rev. B: Condens. Matter Mater. Phys., 2007, 75, 125420.

24 J. P. Perdew, K. Burke and M. Ernzerhof, Phys. Rev. Lett., 1996, 77, 3865-3868.

25 S. Grimme, J. Comput. Chem., 2006, 27, 1787-1799.

26 V. Barone, M. Casarin, D. Forrer, M. Pavone, M. Sambi and A. Vittadini, J. Comput. Chem., 2009, 30, 934-939.

27 A. Kokalj and S. Peljhan, Langmuir, 2010, 26, $14582-14593$.

28 E. R. McNellis, J. Meyer and K. Reuter, Phys. Rev. B: Condens. Matter Mater. Phys., 2009, 80, 205414.

29 K. Tonigold and A. Groß, J. Chem. Phys., 2010, 132, 224701.

30 J. Klimeš and A. Michaelides, J. Chem. Phys., 2012, 137, 120901.

31 A. Kokalj, S. Peljhan, M. Finšgar and I. Milošev, J. Am. Chem. Soc., 2010, 132, 16657-16668.

32 S. Peljhan and A. Kokalj, Phys. Chem. Chem. Phys., 2011, 13, 20408-20417.

33 S. Peljhan, J. Koller and A. Kokalj, J. Phys. Chem. C, 2014, 118, 933-943.

34 A. Kokalj, S. Peljhan and J. Koller, J. Phys. Chem. C, 2014, 118, 944-954.

35 D. Vanderbilt, Phys. Rev. B: Condens. Matter Mater. Phys., 1990, 41, 7892-7895.

36 Ultrasoft pseudopotentials for $\mathrm{H}, \mathrm{C}, \mathrm{N}, \mathrm{O}$, and $\mathrm{Cu}$ were taken from the Quantum Espresso PseudoPotential Download Page: http://www.quantum-espresso.org/pseudopotentials (files: H.pbe-rrkjus.UPF, C.pbe-rrkjus.UPF, N.pbe-rrkjus.UPF, O.pbe-rrkjus.UPF and Cu.pbe-d-rrkjus.UPF), 2015.

37 P. Giannozzi, S. Baroni, N. Bonini, M. Calandra, R. Car, C. Cavazzoni, D. Ceresoli, G. L. Chiarotti, M. Cococcioni, I. Dabo, A. D. Corso, S. de Gironcoli, S. Fabris, G. Fratesi, R. Gebauer, U. Gerstmann, C. Gougoussis, A. Kokalj, M. Lazzeri, L. Martin-Samos, N. Marzari, F. Mauri, R. Mazzarello, S. Paolini, A. Pasquarello, L. Paulatto, C. Sbraccia, S. Scandolo, G. Sclauzero, A. P. Seitsonen, A. Smogunov, P. Umari and R. M. Wentzcovitch, J. Phys.: Condens. Matter, 2009, 21, 395502.

38 A. Kokalj, J. Mol. Graphics Modell., 1999, 17, 176-179.

39 H. J. Monkhorst and J. D. Pack, Phys. Rev. B: Solid State, 1976, 13, 5188-5192.
40 N. Marzari, D. Vanderbilt, A. De Vita and M. C. Payne, Phys. Rev. Lett., 1999, 82, 3296-3299.

41 D. Costa, T. Ribeiro, F. Mercuri, G. Pacchioni and P. Marcus, Adv. Mater. Interfaces, 2014, 1, 1300072.

42 M. Finšgar, S. Peljhan, A. Kokalj, J. Kovač and I. Milošev, J. Electrochem. Soc., 2010, 157, C295-C301.

43 CRC Handbook of Chemistry and Physics, ed. D. R. Lide, CRC Press, Boca Raton, Florida, USA, 74th edn, 1993.

44 C. Li, F. Wang, S. Li, Q. Sun and Y. Jia, Phys. Lett. A, 2010, 374, 2994-2998.

45 K. Reuter and M. Scheffler, Phys. Rev. B: Condens. Matter Mater. Phys., 2001, 65, 035406.

46 L. Bengtsson, Phys. Rev. B: Condens. Matter Mater. Phys., 1999, 59, 12301-12304.

47 A. Kokalj, Phys. Rev. B: Condens. Matter Mater. Phys., 2011, 84, 045418.

48 M. J. Frisch, G. W. Trucks, H. B. Schlegel, G. E. Scuseria, M. A. Robb, J. R. Cheeseman, G. Scalmani, V. Barone, B. Mennucci, G. A. Petersson, H. Nakatsuji, M. Caricato, X. Li, H. P. Hratchian, A. F. Izmaylov, J. Bloino, G. Zheng, J. L. Sonnenberg, M. Hada, M. Ehara, K. Toyota, R. Fukuda, J. Hasegawa, M. Ishida, T. Nakajima, Y. Honda, O. Kitao, H. Nakai, T. Vreven, J. A. Montgomery, Jr., J. E. Peralta, F. Ogliaro, M. Bearpark, J. J. Heyd, E. Brothers, K. N. Kudin, V. N. Staroverov, R. Kobayashi, J. Normand, K. Raghavachari, A. Rendell, J. C. Burant, S. S. Iyengar, J. Tomasi, M. Cossi, N. Rega, J. M. Millam, M. Klene, J. E. Knox, J. B. Cross, V. Bakken, C. Adamo, J. Jaramillo, R. Gomperts, R. E. Stratmann, O. Yazyev, A. J. Austin, R. Cammi, C. Pomelli, J. W. Ochterski, R. L. Martin, K. Morokuma, V. G. Zakrzewski, G. A. Voth, P. Salvador, J. J. Dannenberg, S. Dapprich, A. D. Daniels, Ö. Farkas, J. B. Foresman, J. V. Ortiz, J. Cioslowski and D. J. Fox, Gaussian 09 Revision A.1, Gaussian Inc., Wallingford, CT, 2009.

49 A. Baby, G. Fratesi, S. R. Vaidya, L. L. Patera, C. Africh, L. Floreano and G. P. Brivio, J. Phys. Chem. C, 2015, 119, 3624-3633.

50 G. Mercurio, E. R. McNellis, I. Martin, S. Hagen, F. Leyssner, S. Soubatch, J. Meyer, M. Wolf, P. Tegeder, F. S. Tautz and K. Reuter, Phys. Rev. Lett., 2010, 104, 036102. 